Entrained air in bore-driven swash on an impermeable rough slope

HAN-JING DAI, Department of Civil and Environmental Engineering, Hong Kong

University of Science and Technology, Clear Water Bay, Kowloon, Hong Kong, China

Email: ceamy@ust.hk

GUSTAAF ADRIAAN KIKKERT, Department of Civil and Environmental Engineering,

Hong Kong University of Science and Technology, Clear Water Bay, Kowloon, Hong Kong, China

Email:kikkert@ust.hk

BO-TAO CHEN, Zhejiang Institute of Hydraulics and Estuary, Hangzhou 310020, Zhejiang, China

Email: hhuchenbotao@126.com

DUBRAVKA POKRAJAC, School of Engineering, King's College, University of Aberdeen, Aberdeen, AB24 3UE, United Kingdom

Email:d.pokrajac@abdn.ac.uk 


\title{
Entrained air in bore-driven swash on an impermeable rough slope
}

\begin{abstract}
The aim of the present investigation is to clarify the role and evaluate the importance of air entrainment in the swash zone by carrying out a set of detailed laboratory experiments. Experiments involved generating a single, highly repeatable, large-scale, bore-driven swash event on a sand-rough impermeable beach with slope 1:10. Measurements that yield the characteristics of the entrained air, including the void fractions, bubble size and bed-parallel bubble velocity, and the hydrodynamics are obtained at five crossshore locations in the swash zone using an optical probe and a combined PIV/LIF system. The results show that two distinct bubble clouds enter the swash zone, the first is the result of local entrainment at the wave tip and the second are the remaining bubbles of the air that is entrained at the second plunge point of wave breaking before the wave starts climbing the beach. The void fractions are up to 0.20 and bubble size up to $20 \mathrm{~mm}$ which are similar to air entrainment after wave breaking in the surf zone and deep water. Local entrainment of air continues in the swash zone, but void fractions decrease rapidly with distance up the slope and no air is present after flow reversal. Energy dissipation in the swash zone attributable to entrained air is at least of order $1 \%$ of the total energy dissipation. This is smaller than in the surf zone or deep water because of the smaller volume of entrained air and the greater total energy dissipation in the swash zone.
\end{abstract}

Keywords: bores, entrained air, experimental measurements, hydrodynamics, swash zone

\section{Introduction}

The swash zone is that part of the coastal zone that is alternatively wet and dry. As it is the most landward zone of the coast and the flow in the swash zone has high sediment transport rates, it plays an important role in the morphology of the overall coastal zone, despite its relatively small cross-shore distance (Masselink and Puleo, 2006). The flow in the swash zone is complex as it is unsteady, non-uniform, highly turbulent and has a highly aerated wave tip. Hence to further our understanding and predictions of the changes in the morphology with time, much research has been carried out to firstly understand the fundamental hydrodynamics of the flow in the swash zone (Elfrink and Baldock, 2002, Longo et al., 2002). These have been studied predominantly in the laboratory as the greater control of the initial conditions allowed the various effects on the hydrodynamics to be isolated and studied separately. Recent studies have focused on the flow structures (e.g. Sou and Yeh, 2011, Inch et al., 2015), turbulence (e.g. Petti and Longo, 2001, Sou et al., 2010, Lanckriet and Puleo, 2013, Brinkkemper et al., 2016), effect of bed roughness (e.g. O'Donoghue et al., 2010, Kikkert et al., 2012), effect of permeability (e.g. Steenhauer et al., 2011, Kikkert et al., 2013, Pintado-Patiño et al., 2015), bed shear stress (e.g. Cowen et al., 2003, Barnes et al., 2009, Pujara and Liu, 2014, Jiang and 
Baldock, 2015, Ruju et al., 2016) and swash-swash interactions (e.g. Lo et al., 2013, Pujara et al., 2015, Chen et al., 2016).

These studies have significantly advanced our understanding of the hydrodynamics, however, have so far ignored the aerated nature of the flow. This is also the case for predictions obtained from numerical models based on the non-linear shallow water equations (e.g. Briganti et al., 2011) which treat the flow as a single-phase flow. Desombre et al. (2013) simulated the flow in the swash zone using a 2D Volume of Fluid two-phase model (combined with the Reynolds averaged Navier Stokes equations) and therefore included the entrainment of air bubbles into the flow during wave breaking. Their results indicated that additional air was entrained during successive plunges of the collapsed wave and that the large air cavities broke down into smaller bubbles. By the time the wave tip reached the shoreline, air was well mixed into the flow. Aeration ratios were found to be very high at the wave-tip (above 50\%) and remained high during run-up indicating that air was continuously entrained locally. No air was entrained during backwash and aeration ratios decreased. However, so far it has not been possible to assess the accuracy of the simulated results by Desombre et al. (2013) as there are currently no experimental measurements of the entrained air in the swash zone.

Understanding of the effects of entrained air has been obtained through laboratory experimental studies of flows such as hydraulic jumps (e.g. Chanson and Brattberg, 2000, Kucukali and Chanson, 2008), open channels (e.g. Chanson, 1997, Chanson and Carosi, 2007) and plunging jets (e.g. Cummings and Chanson, 1999, Chanson and Manasseh, 2004). The presence of entrained air also affects many physical processes in the upper-ocean and experimental measurements that yield the characteristics of the entrained bubble clouds after wave breaking have been obtained in deep water and in the surf zone through both laboratory and field studies. Instantaneous void fractions immediately after wave breaking ranged from 0.20 to 0.99 (e.g. Lamarre and Melville, 1991 (laboratory wave flume), Lamarre and Melville, 1992 (laboratory wave flume and field), Deane, 1997 (field), Stokes et al., 2002 (field), Hoque and Aoki, 2008 (laboratory wave flume), Rojas and Loewen, 2010 (laboratory wave flume), Anguelova and Huq, 2012 (laboratory wind-wave tank)). Void fraction remained high for about half the wave period, but decreased rapidly afterwards so that approximately $20 \%$ of the entrained air remained after 0.7 times the wave period (Anguelova and Huq, 2012) or 5\% after a full wave period (Lamarre and Melville, 1991). The peak volume of entrained air was 30 to $60 \%$ greater than the volume of the vortex of air enclosed by the wave during breaking (Blenkinsopp and Chaplin, 2007 (laboratory wave flume)). The minimum bubble size ranged from $30 \mu \mathrm{m}$ to $50 \mu \mathrm{m}$, although equipment limitations did not allow firm limits to be established, and the maximum bubble size ranged from $3 \mathrm{~mm}$ to $64 \mathrm{~mm}$ (e.g. Deane, 1997, Stokes et al., 2002, Blenkinsopp and Chaplin, 2010 (laboratory wave flume)). Penetration of entrained air varied from 0.5 to 2 times the wave height (e.g. Lamarre and Melville, 1992, Deane, 1997, 
Blenkinsopp and Chaplin, 2007, Anguelova and Huq, 2012). The length of the bubble cloud ranged from 0.1 to 0.7 times the wave length (Anguelova and Huq, 2012). Entrainment and detrainment of air contribute to the total amount of energy dissipation during wave breaking. Air entrainment transfers part of the original water energy, contained in a wave prior to breaking, to air. Entrained air therefore has the potential energy equal to the work done by water against the buoyancy force required for maintaining the bubbles at some depth beneath the free surface. It is assumed that the bubbles do not transfer any of this potential energy back to the flow when rising to the free surface and hence upon the escape of the bubbles this potential energy is lost. In deep water and the surf zone values obtained of the total wave energy lost during breaking that was attributable to entrained air varied from 10\% to $40 \%$ (Lamarre and Melville, 1991, Blenkinsopp and Chaplin, 2007, Hoque and Aoki, 2008). To the best of the authors' knowledge similar estimates for the swash zone have not been reported in the literature.

The aim of the present investigation is therefore to clarify the role and evaluate the importance of air entrainment in the swash zone by carrying out a set of detailed laboratory experiments. The characteristics of the entrained air are measured for the first time using an optical probe system, while the hydrodynamic quantities are measured using well-known particle image velocimetry and Laser induced fluorescence techniques. The experiments feature a single non-interacting, dam-break generated, fresh-water and fully turbulent bore that runs up and down an impermeable, rough beach. This simplified set up is similar to that used by Desombre et al. (2013) for their numerical simulation and therefore does not include the effects of suspended sediments, swash interactions and salt content. The experimental data set includes the void fractions, bubble size and bubble velocities of the entrained air as well as the flow depth and velocities. These data can be used in future studies to test and validate numerical results based on two-phase flow equations and as benchmark results for further investigations of the effects of entrained air in real life swash. In the present paper, these results are used to investigate the effect of the entrained air on the flow in the swash zone and assess the assumption that the flow can be modelled as a one phase flow.

\section{Methodology}

\subsection{Experimental Set up}

The experimental set up was based on O'Donoghue et al. (2010) and Kikkert et al. (2012) and employed a dam-break mechanism to generate a plunging wave that resulted in a bore which travelled up and down an impermeable rough slope. The dam-break mechanism generated a single highly repeatable swash event with similar velocities and maximum run-up as encountered in the field (O'Donoghue et al., 2010) and hence scaling issues were absent from the experiments. The glass-sided Armfield SII flume ( $12.5 \mathrm{~m}$ long, $0.45 \mathrm{~m}$ high and $0.30 \mathrm{~m}$ wide) 
located in the Water Resources Laboratory of the Hong Kong University of the Science and Technology was converted to generate a single swash event by positioning a reservoir fronted by a gate at one end of the flume and a 1:10 sloped impermeable beach on the other end (Figure 1). The reservoir, constructed from Perspex had inside dimensions of $1006 \mathrm{~mm} \times 279 \mathrm{~mm} \times 625$ $\mathrm{mm}$ (length $\mathrm{x}$ width $\mathrm{x}$ height) and its bottom was $9 \mathrm{~mm}$ above the flume. Perspex wedges inserted into the flume at the end of the reservoir ensured a smooth transition of the flow from the reservoir into the flume. The gate, constructed from $8 \mathrm{~mm}$ thick aluminium, had flanks constructed in a ' $\mathrm{V}$ ' shape and edges covered in elastic rubber. The gate was attached to a powerful electronic actuator (CMS linear motion system from Bosch Rexroth AG) which was vertically mounted to a Kanya aluminium support framework that was positioned over the flume (Figure 1). The actuator was controlled via software DriveTop 16V14. Raising of the gate started after the software received an external trigger generated using a BNC 575 pulse generator. To minimize any vibrations generated by the actuator, the support framework was attached to the floor and ceiling of the laboratory. The actuator-controlled gate further increased the repeatability of the swash event generated in comparison with O'Donoghue et al. (2010) and Kikkert et al. (2012). Firstly, the actuator was able to repeat the positioning and opening of the gate more accurately, the gate was raised each time to $556 \mathrm{~mm}$ in precisely $0.325 \mathrm{~s}$, and secondly, the downwards force of the actuator yielded a perfect seal for the water in the reservoir and hence the water levels in the reservoir and in front of the reservoir were controlled more accurately.

The distance from the gate to the impermeable 1:10 slope was $3006 \mathrm{~mm}$ (Figure 1). To create a smooth transition for the flow onto the slope, the first $267 \mathrm{~mm}$ consisted of an aluminium wedge. The remaining $4880 \mathrm{~mm}$ of the slope consisted of marine plywood sheets with sediments glued to its surface. The sediments had a $d_{50}$ of $2.0 \mathrm{~mm}$ which is similar to coarse sand particles commonly found in the field on medium sloped beaches. The plywood sheets were supported by an aluminium framework with a slope 1:10. To enable Laser light to illuminate the flow from below, glass slots were inserted into the plywood at five different locations (Figure 2). Partial coverage of the glass slots with sediments meant that only a $5 \mathrm{~mm}$ wide and $200 \mathrm{~mm}$ long slot remained. Sediments were also glued along the edges of the plywood which made sure that the slope was water-tight.

All experiments had identical initial conditions. Fresh water was used and the level in the reservoir was $500 \mathrm{~mm}$ (or $491 \mathrm{~mm}$ above the bottom of the reservoir), and the water level in front of the gate was $50 \mathrm{~mm}$. The water level ratio of 10:1 produced a large plunging breaker that lead to the generation of the fully turbulent bore (Stansby et al., 1998). The point at which the water in front of the gate intersected the beach is defined as the origin of the coordinate system used throughout the paper. The $x$-direction is parallel to the beach and positive 
shoreward and the $z$-direction is normal to the beach and positive upward. Time $t=0 \mathrm{~s}$ is the time when the gate started to be raised by the actuator.

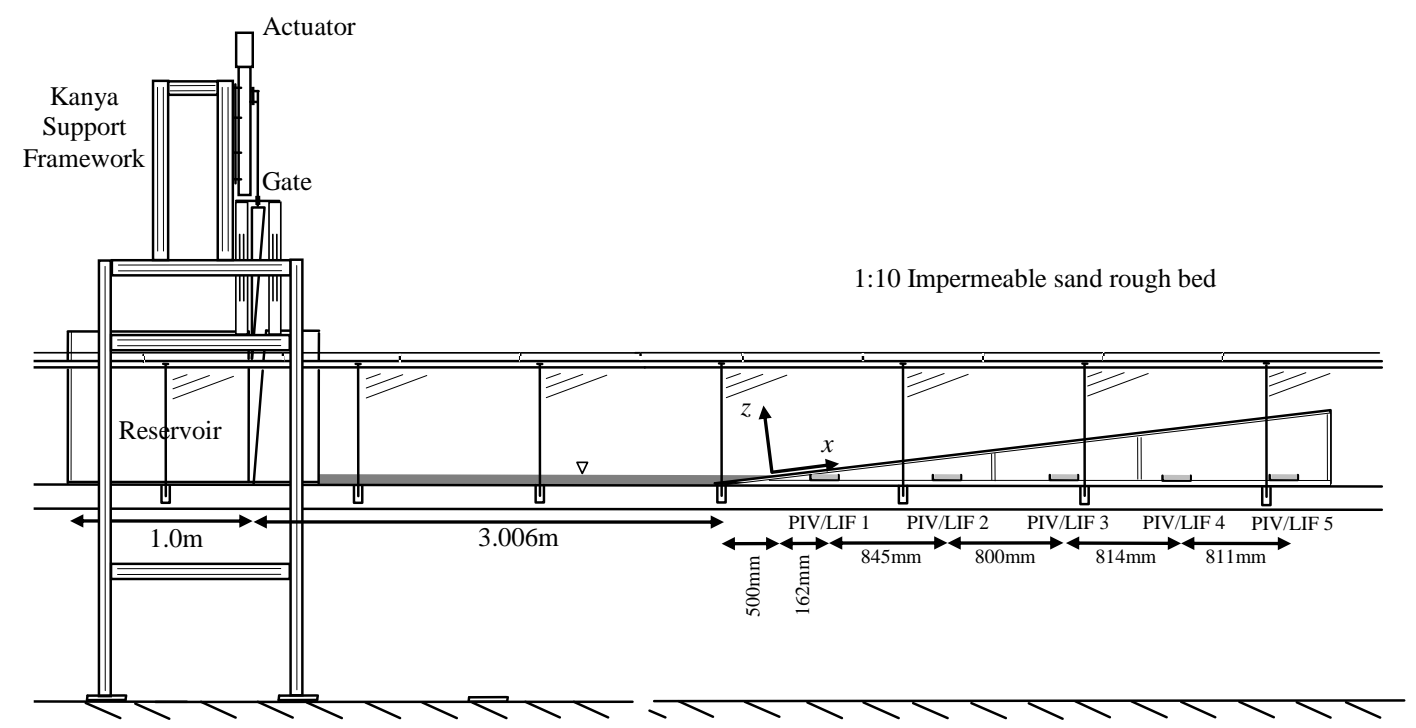

Figure 1 - Experimental set up of dam-break system and impermeable rough bed with locations of PIV/LIF measurements

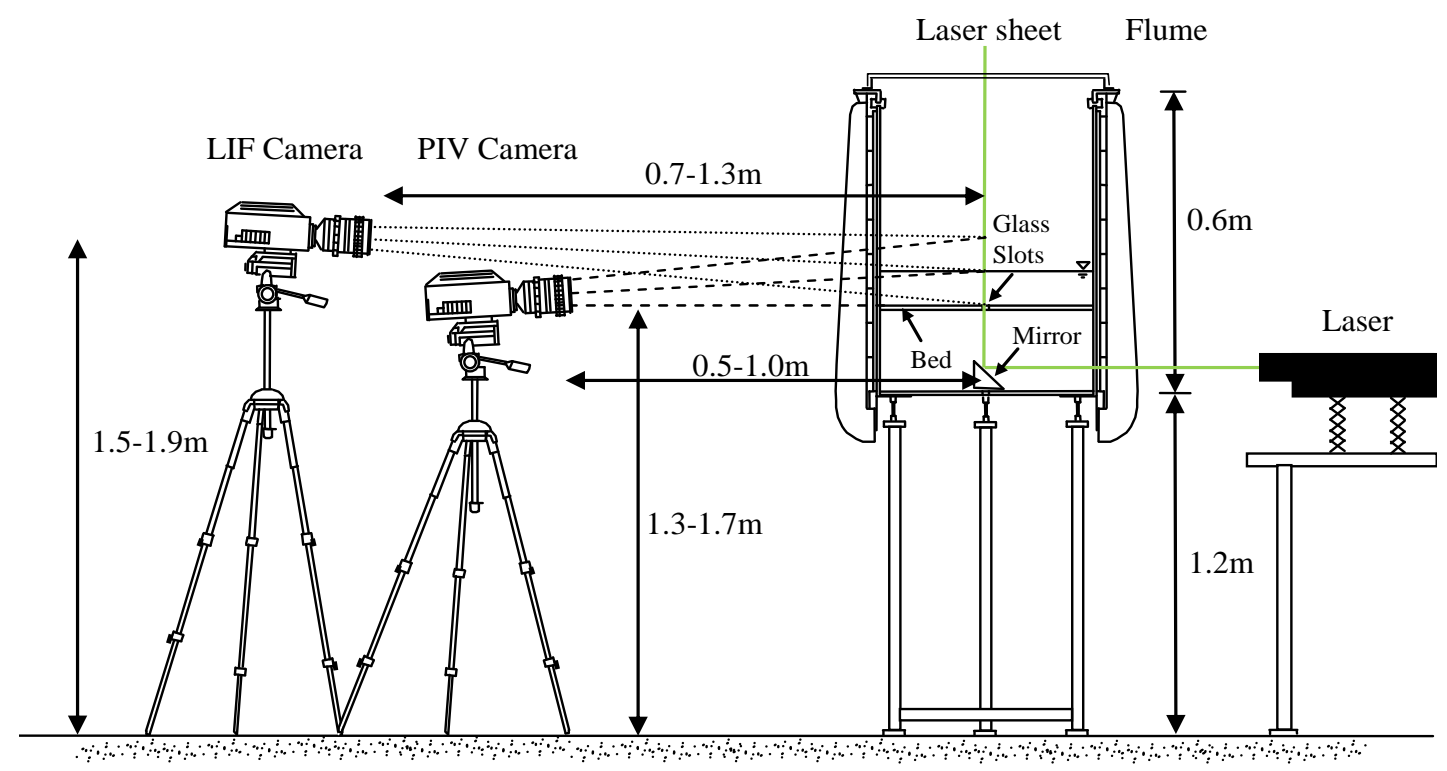

Figure 2 - Experimental equipment set up for PIV/LIF measurements

\subsection{Measurements of Hydrodynamics}

The detailed hydrodynamics of the flow were obtained via a combined Laser induced fluorescence (LIF) and particle image velocimetry (PIV) system (Kikkert et al., 2012) which yielded simultaneous measurements of the flow depth and velocity at the five cross-shore locations ( $x=162 \mathrm{~mm}, 1007 \mathrm{~mm}, 1807 \mathrm{~mm}, 2621 \mathrm{~mm}$ and $3432 \mathrm{~mm}$ ) where glass slots were inserted into the beach. A 5W continuous wave Nd YAG Laser (Dantec Dynamics RayPower 5000) was positioned on one side of the flume (Figure 2). Cylindrical lenses spread the Laser light to generate a horizontal light sheet. To illuminate the flow from below (O'Donoghue et 
al., 2010), the sheet was directed vertically upward using BK 7 right angle prism Laser mirrors positioned below the glass slots and fixed to the support framework of the beach. Rhodamine 590 fluorescent dye with a concentration of approximately $0.025 \mathrm{mg} / \mathrm{L}$ and silver coated hollow glass spheres with mean diameter of $10 \mu \mathrm{m}$, density $1.4 \mathrm{~g} / \mathrm{cm}^{3}$, silver content of $33 \%$ and concentration of approximately $0.50 \mathrm{mg} / \mathrm{L}$ were added to the $175 \mathrm{~L}$ of water in the flume. The emitted light by the fluorescent dye was caught by a Speedsense 9040 digital camera fitted with an orange filter to block any direct Laser light from reaching the camera. The camera was positioned on the other side of the flume to the Laser, rotated to be aligned with the 1:10 slope of the beach and rotated forward so that its field of view was at all times above the free surface. The reflected Laser light from the glass spheres was caught by a second Speedsense 9040 digital camera fitted with a narrowband green filter to block the emitted light by the fluorescent dye. The camera was positioned in front of the LIF camera, rotated to be aligned with the slope and rotated backward so that its field of view was at all times below the free surface. The camera settings and image acquisition were controlled through computer software Dynamic Studio v3.4. Images at 2 megapixel $(1632 \times 1200$ pixels $)$ and 8 bit grey-scale were obtained at a frequency of 50Hz. During each experiment 600 LIF images and 600 PIV image-pairs with a time between images of $1 \mathrm{~ms}$ were recorded. The experiment was repeated 50 times at each location to obtain appropriate ensemble-averaged quantities. The acquisition of images began at $t=0 \mathrm{~s}$ as the software was triggered using the same pulse that also controlled the actuator.

To obtain the swash lens, LIF only experiments were carried out at an additional 13 cross-shore measurement locations along the slope. As only the flow depth was measured, the flow was illuminated from above. The elevation of the Laser was increased by approximately $0.6 \mathrm{~m}$ so that its horizontal light sheet was above the glass walls of the flume. A BK7 right angle prism was positioned along the centreline of the flume to direct the Laser sheet vertically downward. The experiments were repeated 10 times at each location to obtain ensembleaveraged depth measurements. All other parameters were the same as during the PIV/LIF experiments.

Image analysis began by dewarping the images as both cameras were rotated relative to the vertical Laser sheet. The flow depth was obtained from the LIF images by employing an edge detection algorithm to determine the interface between the area of the image that was light (water) and the area of the image that was dark (air). The algorithm yielded the instantaneous flow depth with an accuracy of approximately $0.2 \mathrm{~mm}$, however, the accuracy of the estimates by the algorithm were affected by the very turbulent nature of the flow immediately after bore arrival (especially at $x=162 \mathrm{~mm}$ ) hence these results were confirmed manually. The velocity fields were obtained from the PIV image-pairs via an adaptive cross-correlation algorithm using three iterative steps, $50 \%$ overlap and final interrogation areas of $32 \times 32$ or $16 \times 16$ pixels. The measurement height of the camera field of view was at all locations slightly larger than the 
maximum flow depth which yielded interrogation areas with sizes varying from $0.8 \mathrm{~mm} x$ $0.8 \mathrm{~mm}$ to $3.7 \mathrm{~mm} \times 3.7 \mathrm{~mm}$. A range validation, moving average validation and ensemble average validation were carried out to remove outliers. The estimates for the instantaneous velocities in the $x$-direction $(u)$ and $z$-direction $(w)$ had a random error between $10.5 \mathrm{~mm} / \mathrm{s}$ and $17.9 \mathrm{~mm} / \mathrm{s}$.

The maximum variations in the instantaneous depth and velocities due to turbulence were $20 \mathrm{~mm}$ and $200 \mathrm{~mm} / \mathrm{s}$ respectively and thus larger than the random error due to the system. Using a conservative estimate for the reduction in the error as a result of the ensemble-averaging over the 50 repeat runs of $90 \%$ results in maximum errors in the ensemble-averaged flow depth and ensemble-averaged depth-averaged velocities of $2 \mathrm{~mm}$ and $20 \mathrm{~mm} / \mathrm{s}$ respectively. Away from times of bore arrival and maximum backwash velocity the errors were up to an order of magnitude smaller.

\subsection{Measurements of Entrained Air}

Measurements of the entrained air, including the void fraction, bubble size and bubble velocity, were obtained using a phase detection optical probe system (B-POP) by A2 Photonic Sensors. The measurements of the monofibre optical probes are based on the internal back-reflection method of the Laser beam at the probe tip and the sensitivity of the sensor to the refractive index of the phase in which the probe is submerged. Details of the monofibre optical probe developed by Cartellier (1992) are given in Barrau et al. (1999). Specific details of the A2 Photonic Sensors are given in Pjontek et al. (2014). The probes are able to measure bubble velocities between $0.06 \mathrm{~m} / \mathrm{s}$ and $6.25 \mathrm{~m} / \mathrm{s}$ and detect bubbles with a diameter larger than $100 \mu \mathrm{m}$. The system consisted of an optoelectric module which included the Laser emission and photodetection systems and two phase optical probes with $90^{\circ}$ bends that were connected to the module via fibre optic cables. Data acquisition was obtained via a National Instruments PCI 6115 and the system was controlled via SO6 software. Measurements started at $t=0 \mathrm{~s}$ using the external trigger that also initiated the opening of the gate. The sampling frequency of the probes was $496 \mathrm{kHz}$ and the recording duration was $5 \mathrm{~s}$ which coincided approximately with the time of flow reversal as no entrained air was present in the flow during the backwash. The optical probes yielded time-series of voltage which were converted into a binary signal, where 0 indicated that the probe was submerged in water and 1 that it was submerged in air. A probe holder enabled the optical probes to be positioned at the centre of the flume (Figure 3). The sensing tips were parallel to the slope, $40 \mathrm{~mm}$ apart in the bed-normal direction and faced the incoming bore during the uprush. The probe holder was made from $3 \mathrm{~mm}$ thick aluminium, machined down to $1 \mathrm{~mm}$ for the bottom $170 \mathrm{~mm}$ to minimize the interference to the flow. Measurements of the entrained air were obtained at the same five cross-shore locations where the PIV/LIF measurements yielded the hydrodynamics of the flow. To obtain measurements at 
multiple bed-normal locations above the beach surface, the probe holder was attached to an $x, y, z$ translation stage that was situated cross-wise over the flume. Time-series of the phase of the flow were recorded from $10 \mathrm{~mm}$ above the bed until the maximum free surface height in $10 \mathrm{~mm}$ intervals. Because of the smaller maximum flow depth for locations further up the slope, the number of bed-normal measurement locations was reduced. To obtain appropriate ensemble-averaged void fraction, bubble size and bubble velocity measurements at each bed normal location, the instantaneous results were time-averaged using a frequency of $50 \mathrm{~Hz}$ and ensemble-averaged using the results from 50 repeated experiments. Details of the postprocessing of the optical probe data are given in the Appendix. Calibrations of each individual probe by the manufacturer provide the estimate of the uncertainties of the measurement result for the phase of the flow of 5\%, and for the individual bubble diameter and velocity of 15 to $20 \%$. An accurate estimate of the uncertainty of time-averaged and ensemble-averaged void fraction is difficult, though it is expected to be less than $5 \%$ as a result of the ensembleaveraging. The variation in the diameter and velocity of the bubbles at a location was also greater than the measurement uncertainty. Ensemble-averages for these quantities were calculated only if a minimum of 20 bubbles were available. Based on this, an estimate for the maximum error of the ensemble-averaged quantities is $6 \%$, but this value is much smaller when the number of bubbles available for ensemble-averaging increases.

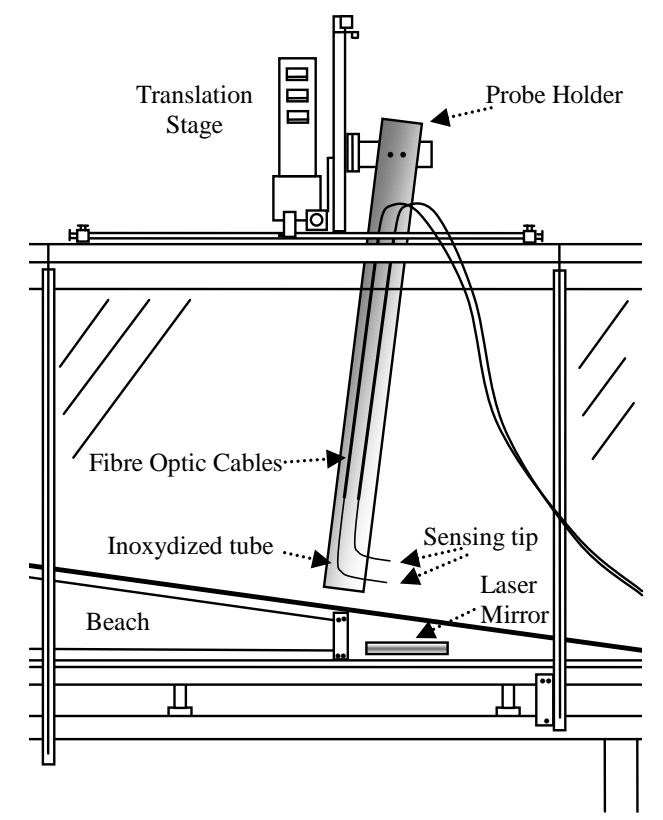

Figure 3 - Experimental equipment set up for phase optical probe measurements

\subsection{Visualization of Entrained Air}

To visualize the behaviour of the entrained air bubbles and qualitatively validate the probe measurements a simplified version of the bubble image velocimetry (BIV) technique (Ryu et al., 2005) was used to obtain high quality images at nine cross-shore locations along the flume. 
The flow was backlit by a high intensity LED panel to yield the outlines of the bubbles and front lit by two $500 \mathrm{~W}$ halogen lamps set at an angle of $60^{\circ}$ to the flume to yield the texture of the bubbles. The images were recorded by the Speedsense 9040 camera and its setup was the same as the PIV camera. The exposure time was set to $0.980 \mathrm{~ms}$, the recording frequency to $1000 \mathrm{~Hz}$ and its duration to 12s. At each location the experiment was repeated 10 times. As for other measurements, recording was triggered at the same time as the gate started to open. The focal plane of the camera was approximately $30 \mathrm{~mm}$ into the flume from the glass wall closest to the camera while the depth of field was maximized to increase the number of bubbles captured in the focal plane. The BIV images showed that the bubble shapes were irregular but were close to spherical for most of the time and hence the maximum bubble size was represented by the longest chord length. At $x=162 \mathrm{~mm}$, the largest bubbles had a size of approximately $20.0 \mathrm{~mm}$ based on the 10 repeated experiments. For locations further up the slope this maximum decreased.

\section{Experimental Results: Hydrodynamics}

Analysis of the PIV/LIF data yielded the swash hydrodynamics, including the flow depths and velocities. The general trends are similar to those obtained by O'Donoghue et al. (2010) and Kikkert et al. (2012), however, the present data highlighted features of the flow not previously mentioned which are discussed below.

Time-series of the ensemble-averaged flow depth, $\bar{h}$, and the ensemble-averaged depth-averaged bed parallel velocity, $\overline{\langle u\rangle}$, at the five locations along the slope are presented in Figure 4(a). The collapse of the plunging wave results in a highly turbulent bore and therefore a very steep bore front which results in a very rapid increase in the flow depth upon arrival of the bore at the initial shoreline location $(x=162 \mathrm{~mm})$ at $t=1.64 \mathrm{~s}$. The maximum flow depth of $0.148 \mathrm{~m}$ is reached $0.84 \mathrm{~s}$ after bore arrival. With the bore generated turbulence dissipating with distance up the slope (Kikkert et al., 2012), the steepness of the bore front decreases and hence the flow depth increase becomes less abrupt. The limited volume of water in the reservoir means that the maximum flow depth is reached before the time of flow reversal, based on the depthaveraged bed-parallel velocity, and the time of flow reversal increases with distance up the slope (Kikkert et al., 2015). The flow depth time-series include periodic fluctuations which Kikkert et al. (2012) related to the plunging wave collapsing into the initial water in front of the gate. Due to the increased repeatability of the swash event during the present experiments these fluctuations are visible in the ensemble-averaged results at all cross-shore locations and even in the backwash. During the second half of the backwash, the flow depth decreases rapidly and approaches zero, however, within the recording duration the flow depth remains non-zero at all measurement locations. 
There is a gap between the time of bore arrival and the first measurement of the depthaveraged velocity shown in Figure 4(b). Any reflected light from the seeding particles was not able to reach the camera during this time due to the presence of the entrained air, so the maximum flow velocity that occurs upon the bore arrival could not be measured. Although somewhat smaller than this maximum, the first measured velocity at each location is still the maximum recorded velocity during the uprush. During the remainder of the uprush, the velocity decreases approximately linearly, though the deceleration is greater for locations further up the slope. The direct comparison of the velocity time-series, not given previously, highlights the divergent nature of the flow during the uprush - at any particular time the velocity at a location further up the slope is greater than the velocity at a lower location. In addition, during the early backwash, the velocity is greater for locations further down the slope. From $x=1007 \mathrm{~mm}$ shoreward the acceleration of the flow gradually decreases until just before the time of maximum backwash velocity. The exception is $x=162 \mathrm{~mm}$, where during the early backwash the acceleration of the flow decreases more quickly than at other locations, resulting temporarily in a lower velocity at $x=162 \mathrm{~mm}$ than at $x=1007 \mathrm{~mm}$. The Froude number, calculated as $\overline{\langle u\rangle} / \sqrt{g h}$, shows that after flow reversal, the flow is initially subcritical at all locations, but as the velocity increases the flow becomes supercritical (Figure 4(c)). However, the acceleration of the flow at $x=162 \mathrm{~mm}$ is hampered by the water present above the horizontal section of the experimental set up which represents the effects of the surf zone. Therefore the acceleration decreases faster and the flow at $x=162 \mathrm{~mm}$ remains subcritical for longer. Eventually, the increase in the velocity and decrease in the flow depth means that the flow at $x$ $=162 \mathrm{~mm}$ becomes supercritical as well $(t=6.06 \mathrm{~s})$, the downstream water stops affecting the acceleration which hence increases temporarily (until $t=6.12 \mathrm{~s}$ ) yielding a velocity that is greater than at $x=1007 \mathrm{~mm}$ once more. Afterwards the gradual decrease in acceleration resumes until the flow at $x=162 \mathrm{~mm}$ also reaches the time of maximum backwash velocity. During the remainder of the swash event the velocity quickly reduces and again approaches zero.

The bed-normal velocities in the swash zone are significantly smaller than the bedparallel velocities (e.g. Kikkert et al., 2012) and sufficiently small that simulation models of the swash flow based on the non-linear shallow water equations (e.g. Briganti et al., 2011), which assume the velocity is zero, yield reasonable predictions of the hydrodynamics. Time-series of the ensemble-averaged depth-averaged bed-normal velocity, $\overline{\langle w\rangle}$, shown in Figure 5, were not reported in the literature. Note that after the time of maximum backwash velocity in the bedparallel direction, the rapidly decreasing flow depth resulted in increasing errors in the depthaveraged bed-normal velocity estimates. The figure confirms that the magnitude of the bednormal velocity is relatively small compared to the bed-parallel velocity, however, the velocity is not necessarily zero. Rising bubbles would induce negative bed-parallel velocities, but these 
are not responsible for the non-zero velocity measurements as the measurements could only be obtained after the entrained air had passed the measurement locations. The time-series show periodic fluctuations at all locations and these are directly related to the fluctuations already seen in the flow depth time-series. Immediately after bore arrival, these fluctuations affect the upper half of the bed-normal velocity profiles (not shown here). However, as the magnitude of the fluctuations decrease with time, the part of the profile affected becomes limited to that close to the free surface. At $x=162 \mathrm{~mm}$, the bed-normal velocities after bore arrival are negative. A small increasing trend results in the velocity becoming positive around the time of flow reversal and reaching a maximum positive velocity just before the time of maximum backwash velocity in the bed-parallel direction. After wave breaking the bore travels horizontally, but when it reaches the initial shoreline location the incoming flow is forced to change direction to become parallel with the inclined slope. The negative velocities at $x=162 \mathrm{~mm}$ and to a lesser extend $x$ $=1007 \mathrm{~mm}$, indicate that this process is not complete by the time the flow reaches these locations and the velocity profiles show that this affects the flow throughout most of the flow column. During the backwash, the flow leaving the swash zone again changes direction at the initial shoreline location, resulting in positive bed-normal velocities.

(a)

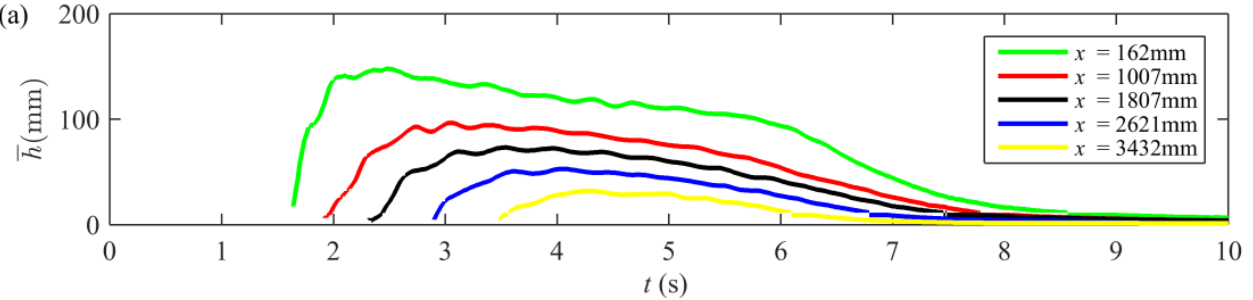

(b)

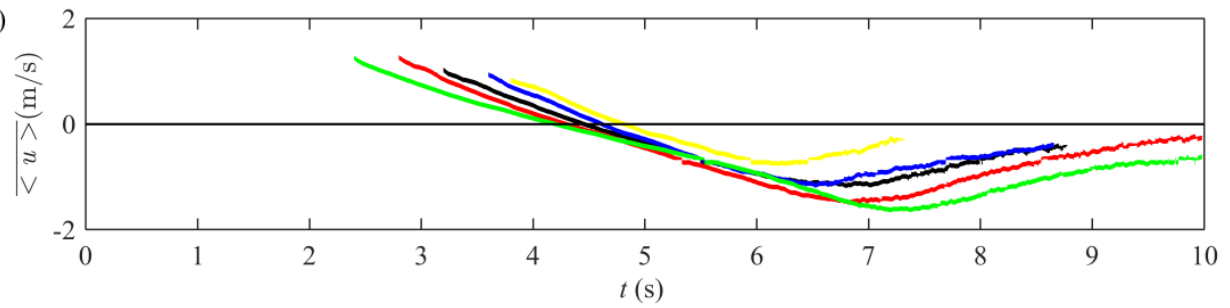

(c)

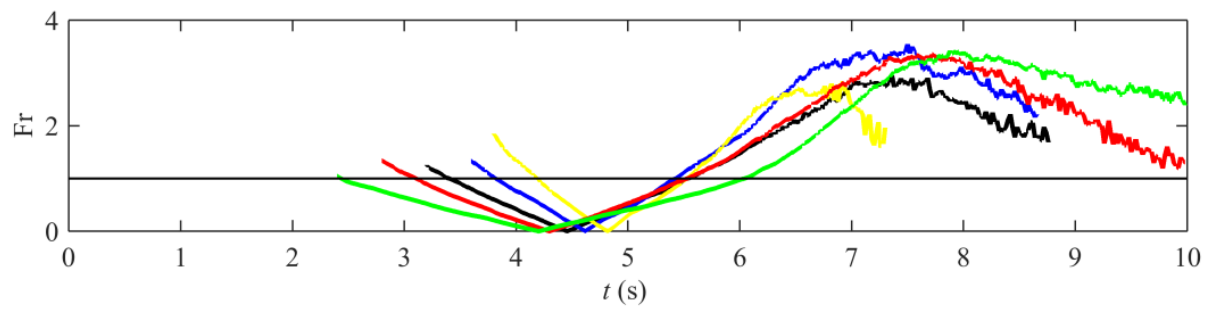

Figure 4 - Time-series of the ensemble-averaged flow depth (a), ensemble-averaged depth-averaged bedparallel velocity (b) and Froude Number (c). 

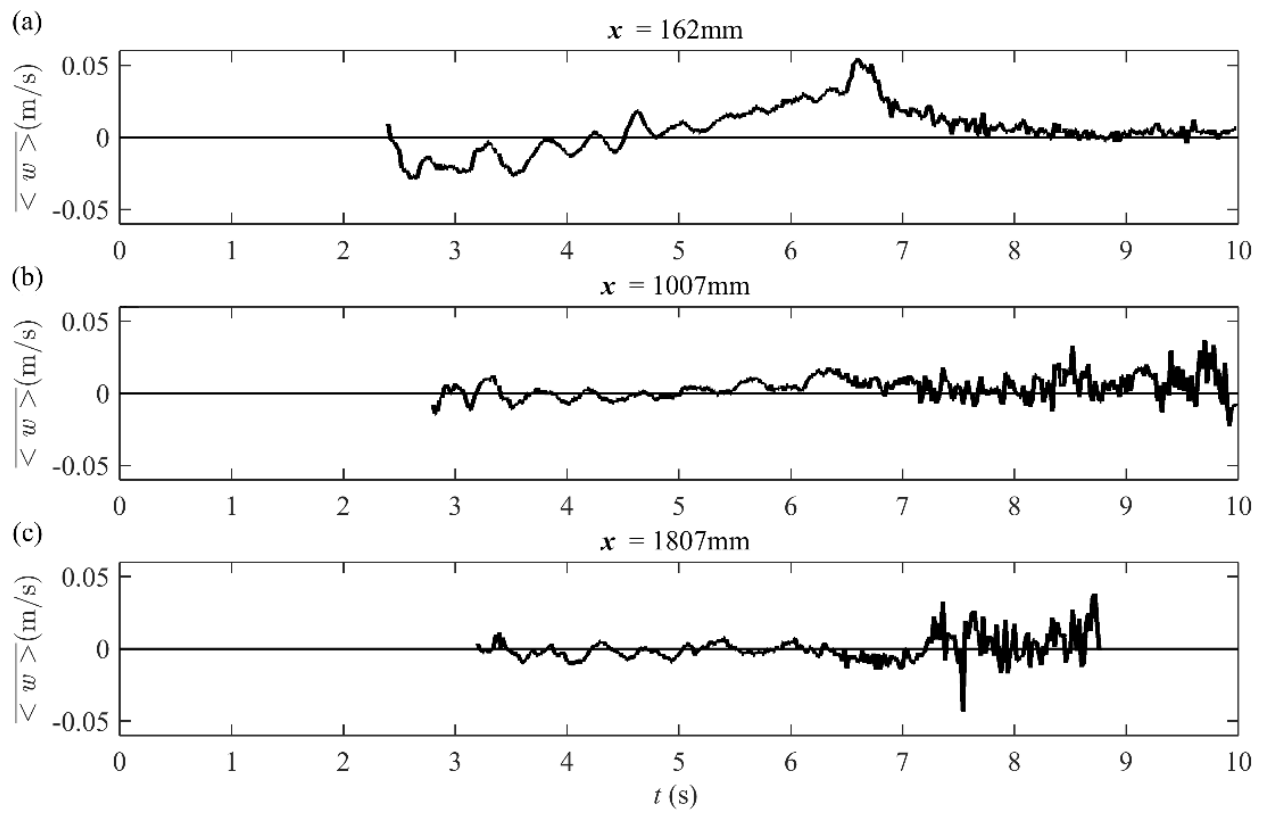

Figure 5 - Time-series of the ensemble-averaged depth-averaged bed-normal velocity at $x=162 \mathrm{~mm}(\mathrm{a}), x=$ $1007 \mathrm{~mm}$ (b) and $x=1807 \mathrm{~mm}(\mathrm{c})$.

\section{Experimental Results: Entrained Air}

\subsection{Visual Observations}

Example BIV images obtained at the first PIV/LIF location are presented in Figure 6 and 7 in order to show the general structures of the entrained air that travels with the flow into the swash zone. The bubbly flow can be separated into distinct regions which are present in all 50 repeated experiments. Firstly, there is a region with a high density of bubbles as the bore first arrives the wave-tip bubble cloud (Figure 6(a)). It is formed as a result of the natural aeration process during the propagation of the highly turbulent bore front. Because of the short time since entrainment, the air inside the wave-tip bubble cloud has had very little time to develop into a large number of small bubbles of approximately uniform size and hence large bubbles are still present (Deane and Stokes, 2002). The wave-tip bubble cloud is followed by a region with relatively few bubbles (Figure 6(b)). As the flow passes the measurement location, this region begins at the free surface and eventually reaches the bottom boundary. A second region with a high density of bubbles, the wave-plunge bubble cloud, is located in the upper part of the flow column (Figure 6(c)). It also begins at the free surface and increases in height as the bubble cloud passes the measurement location. At maximum thickness, it covers approximately twothirds of the flow column. The air present in this bubble cloud is entrained by the flow during the collapse of the second surge (or the time around the second plunge point) which occurs approximately $0.88 \mathrm{~s}$ after gate opening. Therefore there is time, between the entrainment of the bubbles and the bubbles reaching the swash zone, for the bubbles to develop and hence large 
bubbles are absent. There is also sufficient time for bubbles to rise and hence a significant number of bubbles have escaped the flow before it reaches the swash zone. The remaining bubbles are concentrated near the top of the flow column (Figure 6(d)). The end of the waveplunge bubble cloud is considered the end of the aerated region of the flow that enters the swash zone. Only a few individual bubbles trail the aerated region. These bubbles are entrained during the initial collapse of the plunging wave (or the time around the first plunge point). However, there is sufficient time for nearly all bubbles to escape the flow before it reaches the swash zone.

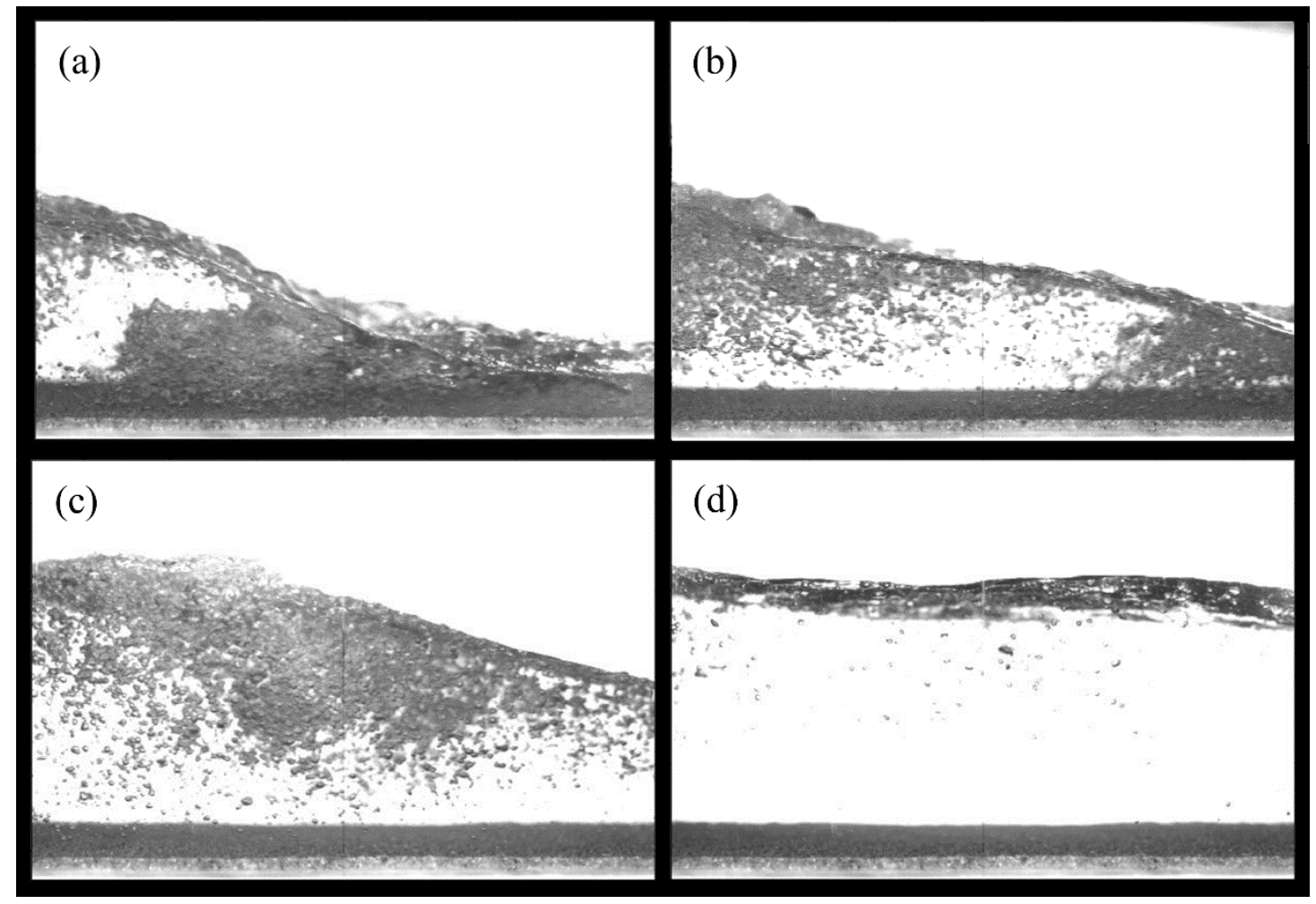

Figure 6 - Example BIV images of incoming bore travelling from left to right at $x=162 \mathrm{~mm}$ showing the air bubbles (dark regions) in the wave-tip bubble cloud (a), region of relatively few bubbles (b), wave-plunge bubble cloud (c) and trailing bubbles (d).

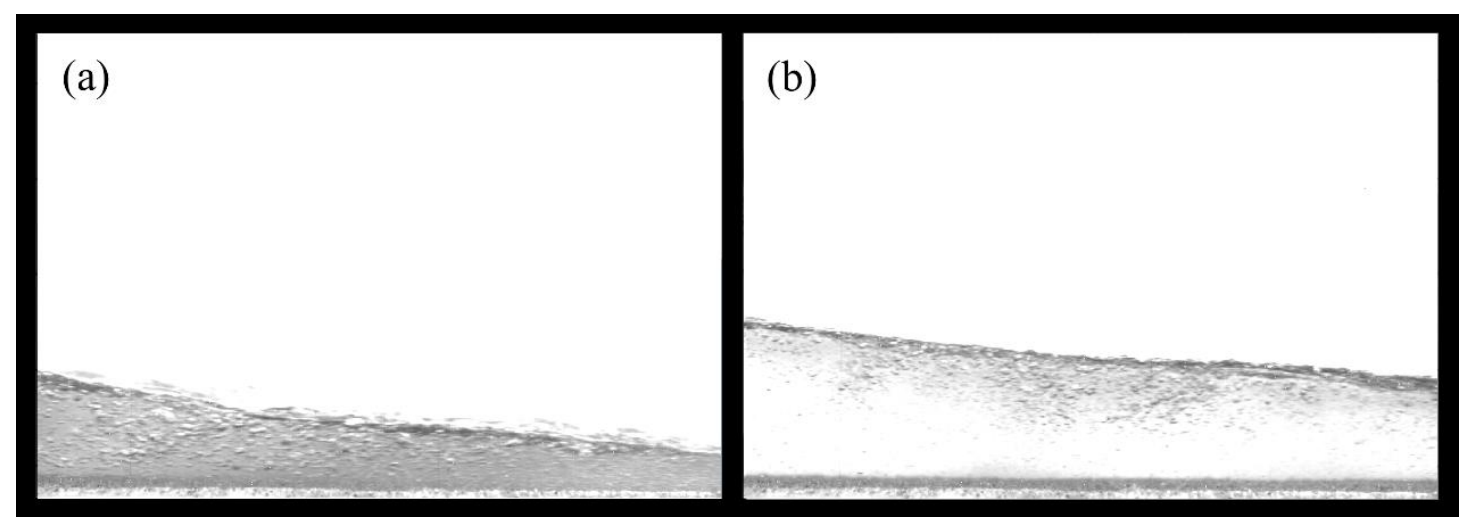

Figure 7 - Example BIV images of incoming bore travelling from left to right at $x=1007 \mathrm{~mm}$ showing the air bubbles (dark regions) in the wave-tip bubble cloud (a) and wave-plunge bubble cloud (b). 
BIV images obtained further up the slope reveal the evolution and disappearance of the bubble clouds. The wave-plunge bubble cloud is still present when the flow travels past $x=$ $1007 \mathrm{~mm}$ (Figure 7), however, it has a smaller size and density and the remaining bubbles are concentrated near the free surface. As the bore rushes up the slope at high speed aeration can still be observed near the bore tip. However, bore generated turbulence becomes progressively smaller as the bore strength decreases. This results in a decrease in the volume of entrained air. In addition, the smaller flow depth further up the slope enables the bubbles to escape the flow sooner after entrainment. This means that at $x=1807 \mathrm{~mm}$, the number of bubbles at the bore tip has again reduced significantly and only a few bubbles are present in the remainder of the flow. At locations further shoreward, bubbles are only found at the bore tip. Very few bubbles are present in the flow during the backwash.

The experimental observations qualitatively agree with the numerical prediction by Desombre et al. (2013): air is entrained at multiple plunge points, large air cavities break down quickly into smaller bubbles and local entrainment of air at the wave-tip continues during the uprush. However, the experiments show that air escapes the flow much more quickly than predicted in Desombre et al. (2013) where a relatively long cross-shore region of high air content remained throughout the uprush and backwash.

\subsection{Void Fraction}

Ensemble-averaged void fraction profiles obtained at $x=162 \mathrm{~mm}$ are shown in Figures 8 . Because the flow depth fluctuated by up to $25 \mathrm{~mm}$ immediately after bore arrival, it is more appropriate to calculate the intrinsic average, i.e. to average over the number of experimental runs when the probe was submerged (Pokrajac and Kikkert, 2011). At time instances when the fluctuations in the flow depth was significant, non-zero values for the ensemble-averaged void fractions occur also above the ensemble-averaged flow depth. The void fractions are used to determine the duration of the two kinds of bubble clouds observed in BIV images (Figure 6). The wave-tip bubble cloud causes large void fractions near the bed immediately after bore arrival. With time the flow depth rapidly increases and lifts the bubble and the associated peak void fraction within the profile further away from the bed. In addition, the peak magnitude of the void fraction increases as more air is entrained into the flow (particularly at heights of 30 to $50 \mathrm{~mm}$ above the bed). The maximum void fraction of the wave-tip bubble cloud (Figure 8) is approximately 0.20 and occurs at $t=1.74 \mathrm{~s}$. From $1.76 \mathrm{~s}$ onwards, little further entrainment of air bubbles occurs and hence the void fraction decreases again until it reaches a very small value that represents the trailing bubbles at 1.92s. The duration of the wave-tip bubble cloud is therefore estimated as $0.28 \mathrm{~s}$. During this period, the presence of the wave-plunge bubble cloud also becomes noticeable, e.g. at 1.80s two peaks can be seen in the profile (i.e. the lower peak due to the wave-tip bubble cloud and the upper peak due to the wave-plunge bubble cloud). 
The magnitude of the peak of the wave-plunge bubble cloud increases more gradually than for the wave-tip bubble cloud and reaches a maximum of 0.18 at 2.04s. This maximum is located close to the free surface as entrained bubbles have started to rise. Within the first $30 \mathrm{~mm}$ away from the free surface the void fraction reduces by up to $90 \%$, however, it only becomes zero at about $z=50 \mathrm{~mm}$. At $t=2.20 \mathrm{~s}$, the void fraction at the free surface decreases to that of the discrete bubbles trailing the bubble clouds and hence the duration of the wave-plunge bubble cloud is approximately $0.40 \mathrm{~s}$.
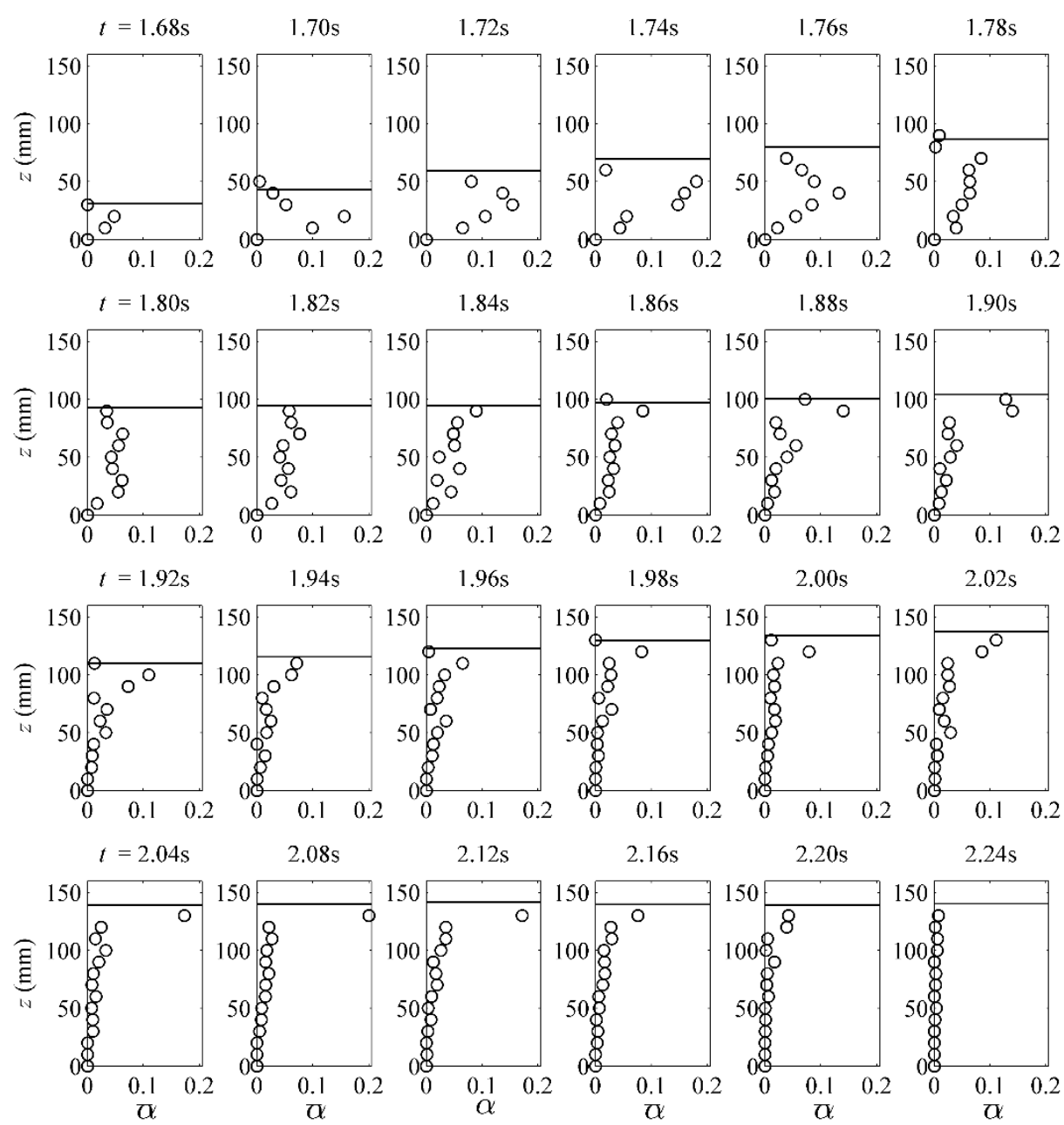

Figure 8 - Ensemble-averaged void fraction profiles at $x=162 \mathrm{~mm}$ from $t=1.68$ to $2.24 \mathrm{~s}$ in $0.02 \mathrm{~s}$ or $0.04 \mathrm{~s}$ intervals, horizontal black line indicates corresponding ensemble-averaged flow depth. 

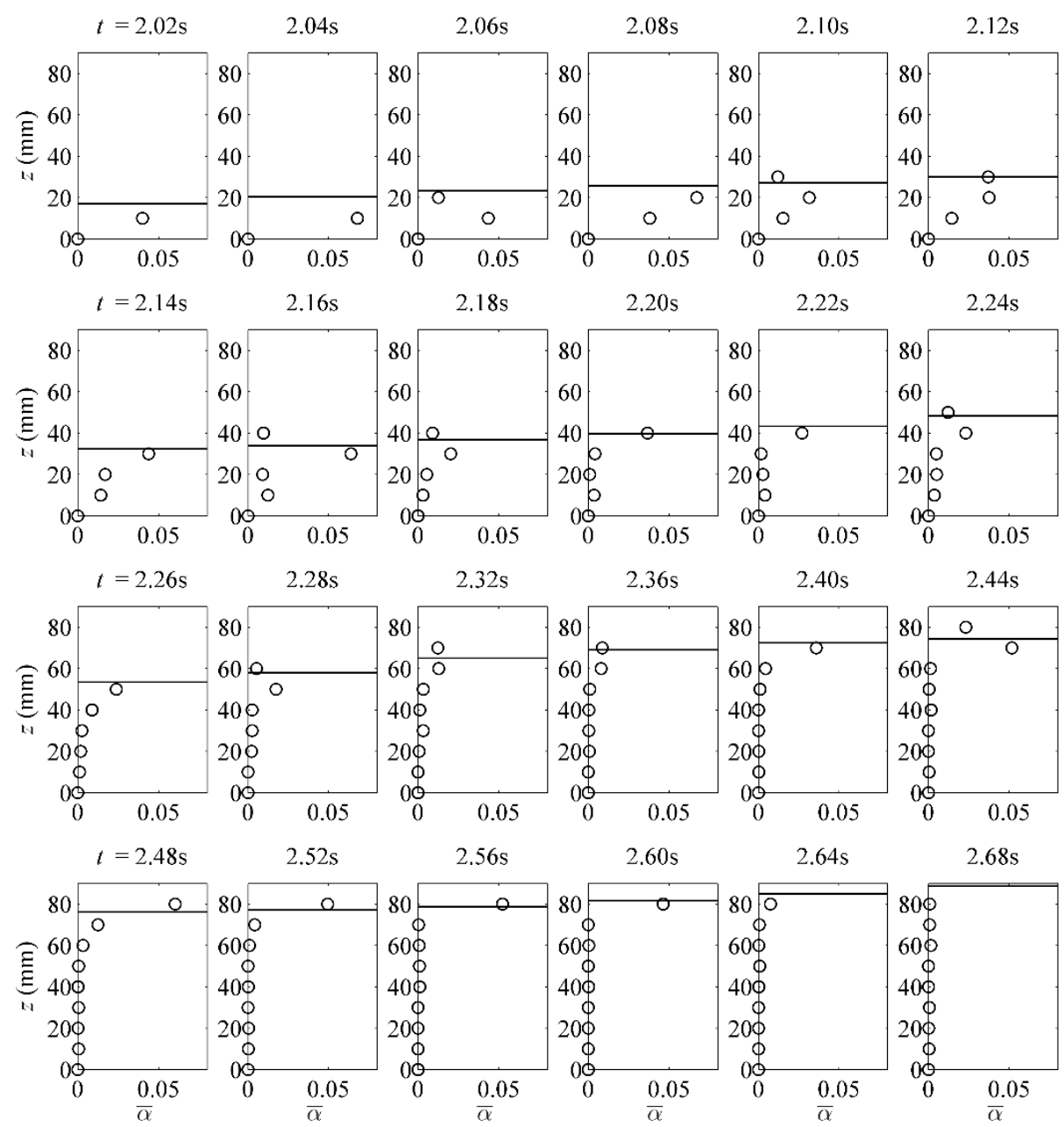

Figure 9 - Ensemble-averaged void fraction profiles at $x=1007 \mathrm{~mm}$ from $t=2.02$ to $2.68 \mathrm{~s}$ in $0.02 \mathrm{~s}$ or $0.04 \mathrm{~s}$ intervals, horizontal black line indicates corresponding ensemble-averaged flow depth

After bore arrival, the profiles at $x=1007 \mathrm{~mm}$ (Figure 9) have a similar trend as at $x=$ $162 \mathrm{~mm}$ due to the local entrainment of air at the wave-tip. The peak is near the bed, but as the flow depth increases so does the distance between the bed and the location of the peak. However, the wave-tip is much less turbulent and hence entrains less air. Therefore the maximum value of the void fraction is 0.07 . The wave-tip bubble cloud has passed $x=1007 \mathrm{~mm}$ by $t=2.30 \mathrm{~s}$ and therefore the duration of the wave-tip bubble cloud is estimated as $0.35 \mathrm{~s}$. Afterwards only the measurements of the void fraction closest to the free surface are not zero. The BIV results indicated that these bubbles are the remains of the wave-plunge bubble cloud at $x=162 \mathrm{~mm}$ as the majority of bubbles from the wave-plunge bubble cloud have escaped the flow. The void fraction profiles therefore confirm the BIV observations that the bubble clouds are significantly smaller than at $x=162 \mathrm{~mm}$. The maximum value of the void fraction has been reduced by $65 \%$ and the total duration of the bubble clouds has been reduced by almost $50 \%$. 
In comparison to wave breaking observations in the surf zone and deep water (e.g. Lamarre and Melville, 1992, Deane, 1997, Rojas and Loewen, 2010), the magnitude of the maximum void fraction in the swash zone is similar. However, in the surf zone relatively high void fractions were measured for up to half the wave period after wave breaking, which was therefore of the order of several seconds. Based on the present experimental results, the rapid reduction in the void fraction with distance up the slope indicates that in the swash zone the duration of relative high void fraction may be an order of magnitude smaller.

\subsection{Bubble size}

The optical probes yielded the chord length of each individual bubble. Assuming that the bubbles are spherical then the chord length is equal to the diameter, $d$. The BIV observations showed that this assumption is generally acceptable with the exception of some of the largest bubbles immediately after entrainment. Based on the results from the ensemble-averaged void fraction profiles, the bubbles that make up the wave-tip and wave-plunge bubble clouds are isolated from all bubbles collected at $x=162 \mathrm{~mm}$ and the bubble diameter probability density functions (pdf) for the two bubble clouds are presented in Figure 10. The figure shows that in the wave-tip bubble cloud a number of large bubbles with diameters between 12 and 20mm exist as a result of the local entrainment at the bore tip which confirms the observations from the BIV images. The maximum bubble diameter of $20 \mathrm{~mm}$ is similar to that reported by previous studies focusing on wave breaking in the surf zone and deep water (Deane, 1997, Stokes et al., 2002, Kalvoda et al., 2003 (laboratory wind-wave tank)), though smaller than the $64 \mathrm{~mm}$ measured by Blenkinsopp and Chaplin (2010). Within the wave-tip bubble cloud, these large bubbles split into fine bubbles and this results in a wider size range than for the wave-plunge bubble cloud in which bubbles of large size have already disappeared. There are two obvious relationships between the pdf and bubble diameter. For bubbles smaller than approximately $2.5 \mathrm{~mm}$, there is only a weak dependence as bubbles are stabilized by surface tension, while for bubbles greater than approximately $2.5 \mathrm{~mm}$ there is a power law relationship as bubbles break up into smaller bubbles due to turbulence and shear (Hinze, 1955). The bubble diameters of $2.5 \mathrm{~mm}$ that separates the two relationships matches well the values obtained by Deane and Stokes (2002) and Blenkinsopp and Chaplin (2010) in deep water. The exponent of the power law relationship for the wave-tip bubble cloud is -2.2 (Figure 10(a)) which is within the range obtained by Blenkinsopp and Chaplin (2010) but smaller than Deane and Stokes (2002). The absence of large bubbles within the wave-plunge bubble cloud results in an increase of the power exponent to -2.8 (Figure 10(b)). Deane and Stokes (2002) concluded that during wave breaking in deep water bubbles are generated with diameters down to at least $50 \mu \mathrm{m}$ which indicates that bubbles with a diameter smaller than the detection limit of the experimental 
equipment may also be present in the swash-zone, but these smaller bubbles do not affect the exponents of the power law relationships for the bubble clouds.
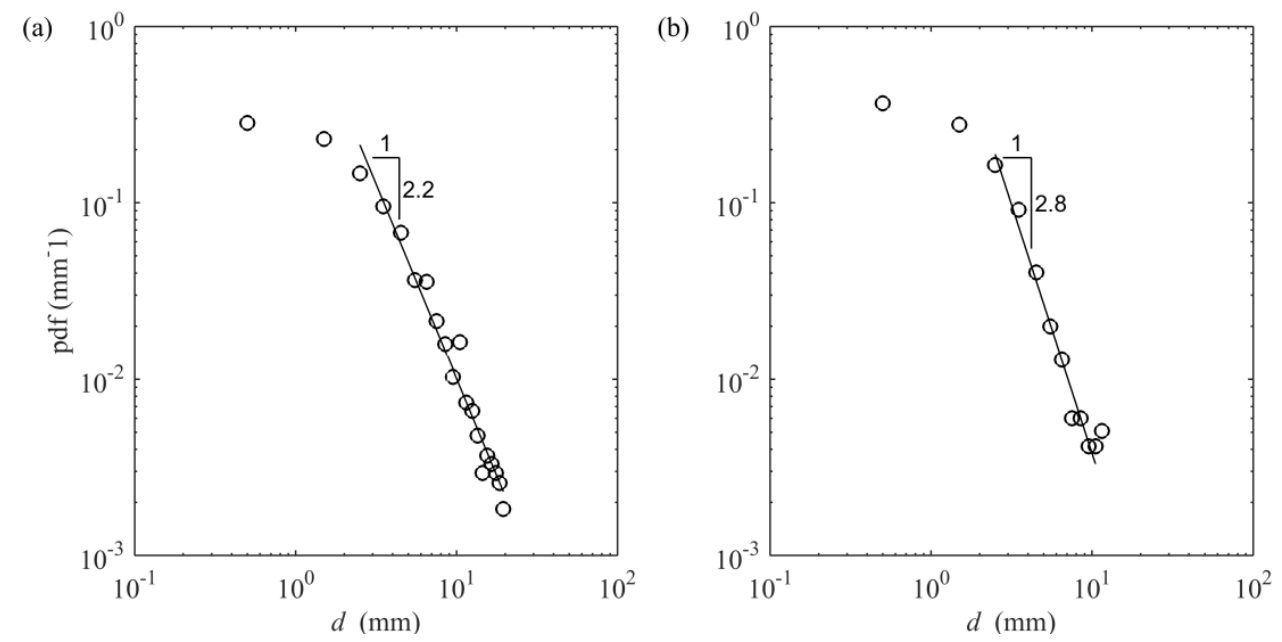

Figure 10 - Bubble diameter probability density function of the wave-tip bubble cloud at $x=162 \mathrm{~mm}$ (a) and the wave-plunge bubble cloud at $x=162 \mathrm{~mm}$ (b)

The ensemble-averaged bubble diameter, $\bar{d}$, at time $t$ and height $z$ is obtained via the intrinsic averaging method and using the bubbles from the fifty repeated experiments and the time-averaging frequency of $50 \mathrm{~Hz}$. The results show that the bubble size depends on the bednormal location, bed-parallel location and time. At $x=162 \mathrm{~mm}$ (Figure 11), the largest bubbles are present as soon as the bore arrives. The size of the bubbles near the bed $(z=10$ and $20 \mathrm{~mm})$ are approximately $3 \mathrm{~mm}$ and similar to those in the upper layers $(z=60$ and $70 \mathrm{~mm})$. However, the bubbles at the front of the cloud in the middle layers (and in particular at $z=40 \mathrm{~mm}$ ) are up to $8 \mathrm{~mm}$. These heights coincide with the heights at which the majority of the local entrainment of air takes place as indicated by the largest void fractions (Figure 8). This natural aeration process initially results in large air cavities in the flow. With time these air cavities develop into a larger number of fine bubbles and hence the bubble size gradually decreases until it is largely independent of height by the time the wave-tip bubble cloud has passed. From $t=1.92 \mathrm{~s}$ onwards all results can be attributed to the wave-plunge bubble cloud. During this time, the bubble size remains approximately constant and away from the free surface is largely independent of the vertical location. The average bubble diameter is $1.6 \mathrm{~mm}$ with $80 \%$ of the bubbles between $1 \mathrm{~mm}$ and $3 \mathrm{~mm}$. Note that during this stage the bubbles near the free surface, initially at $z=120 \mathrm{~mm}$ and later $130 \mathrm{~mm}$, are up to three times larger. This is the result of the bubbles that float upward and reach the free surface, but do not immediately escape due to surface tension. Instead smaller bubbles combine until their combined buoyancy force is sufficient to overcome surface tension and escape (Wood, 1991). This process also explains why the void fraction near the free surface of the wave-plunge bubble cloud is more than an order of magnitude larger than for the rest of the cloud (Figure 9). In the wave-tip bubble cloud at $x=1007 \mathrm{~mm}$ (Figure 12), the bubbles with the largest diameter within the profile are those closest to the free surface as a result of the local 
aeration. However, the entrained bubbles are up to three times smaller than further down the slope because of the less turbulent flow at the wave tip. The air bubbles at $z=70 \mathrm{~mm}$ and $80 \mathrm{~mm}$ are what remains of the wave-plunge bubble cloud at $x=162 \mathrm{~mm}$. Hence the bubble size is still independent of time and vertical height and has an average value of $1.6 \mathrm{~mm}$. Further up the slope, the size of the locally entrained bubbles decreases. In addition, the bubbles trailing the wave-tip bubble cloud are no longer remains of the wave-plunge bubble cloud, but instead are remains of the wave-tip bubble cloud at locations further down the slope. Hence the size of these bubbles decreases as well.
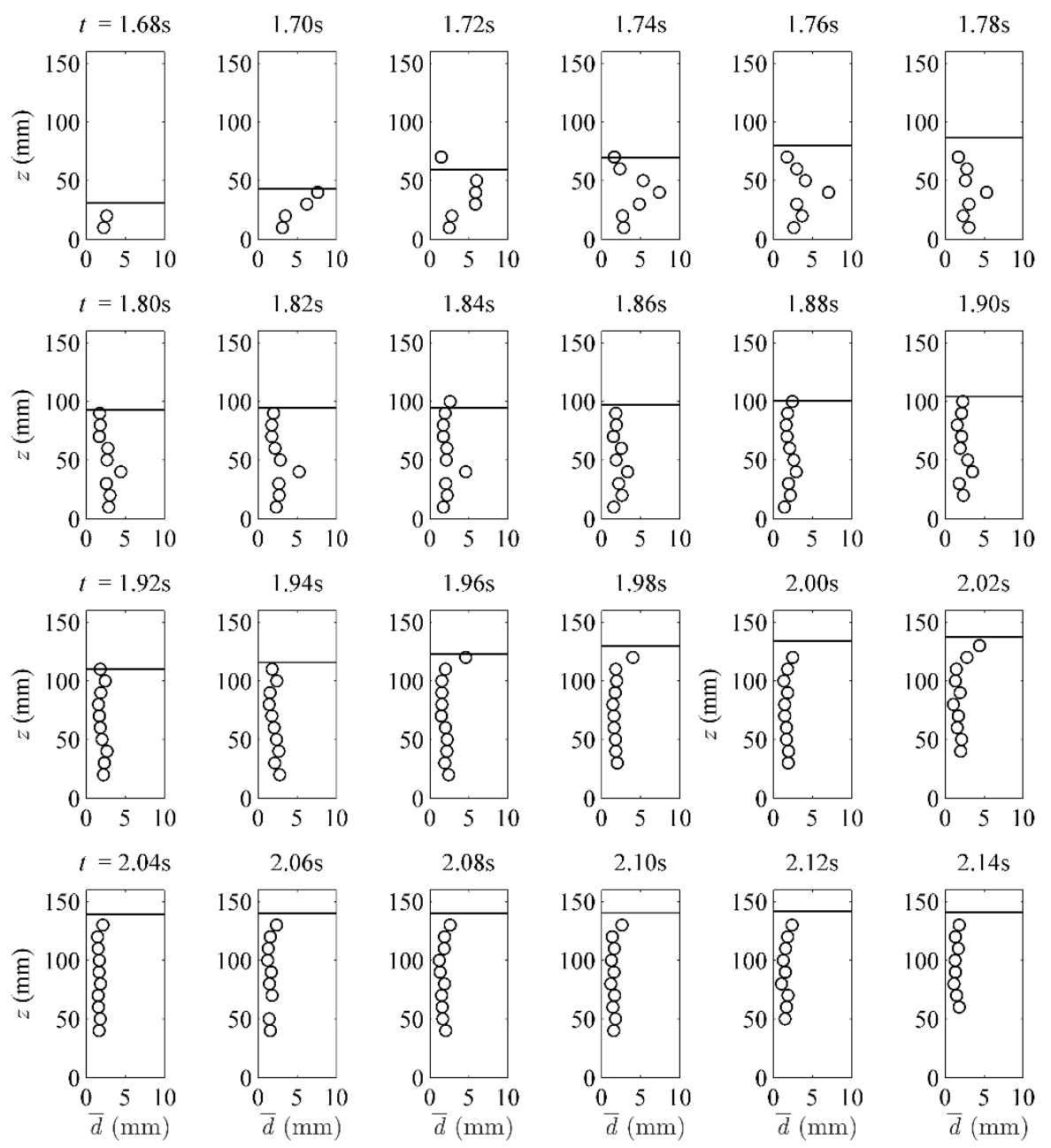

Figure 11 - Ensemble-averaged bubble diameter profiles at $x=162 \mathrm{~mm}$ from $t=1.68$ to $2.14 \mathrm{~s}$ in $0.02 \mathrm{~s}$ intervals, horizontal black line indicates corresponding ensemble-averaged flow depth. 

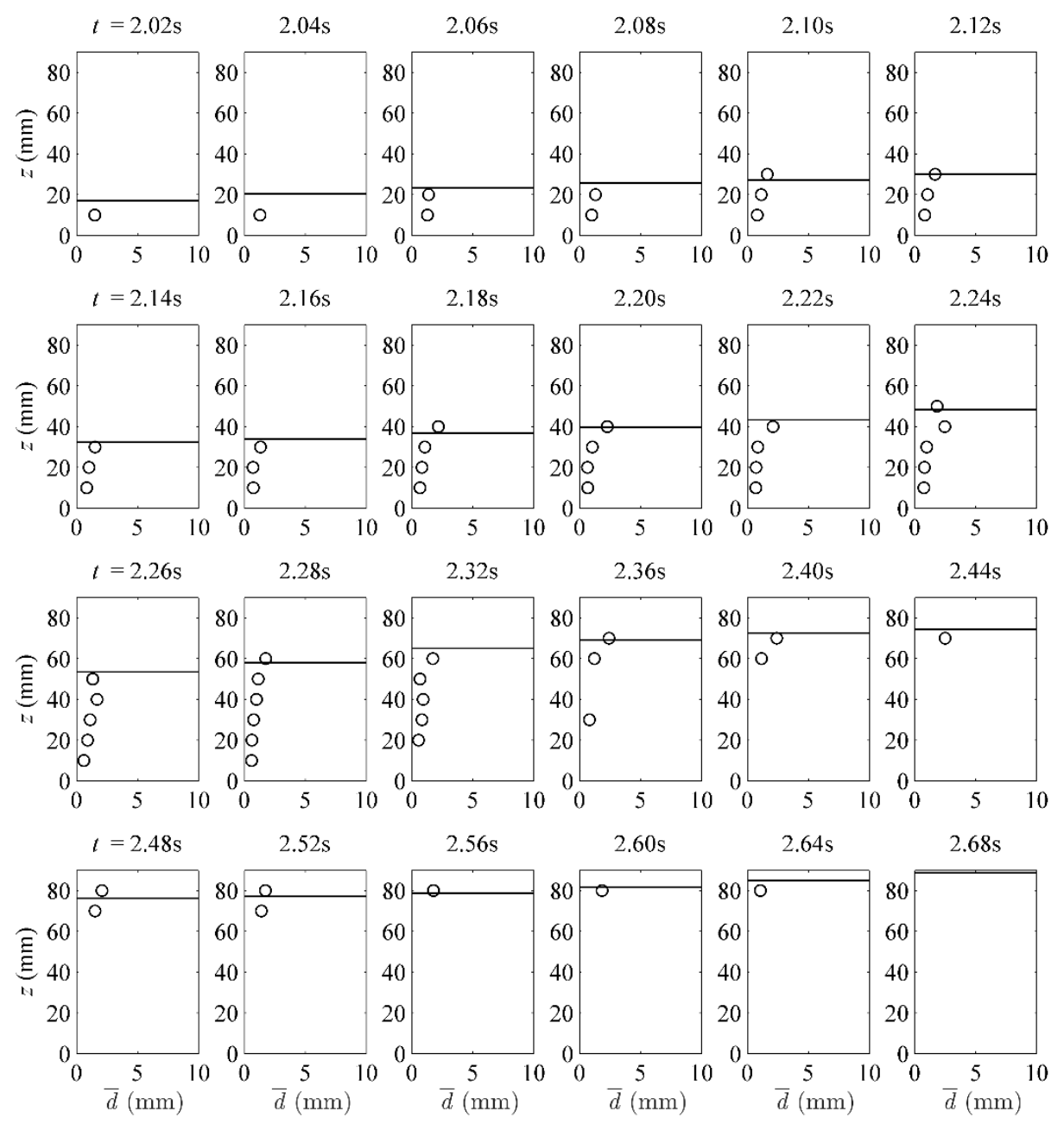

Figure 12 - Ensemble-averaged bubble diameter profiles at $x=1007 \mathrm{~mm}$ from $t=2.02$ to $2.68 \mathrm{~s}$ in $0.02 \mathrm{~s}$ or $0.04 \mathrm{~s}$ intervals, horizontal black line indicates corresponding ensemble-averaged flow depth.

\subsection{Bubble velocity}

Based on the assumption of spherical bubbles, the optical probes also yielded the bed-parallel velocity of the bubbles. The ensemble-averaged bubble velocity, $\overline{u_{b}}$, at time $t$ and height $z$ is once again obtained via the intrinsic averaging method and using the bubbles from the 50 repeated experiment and the time-averaging frequency of $50 \mathrm{~Hz}$. The ensemble-averaged bubble velocity profiles at $x=162 \mathrm{~mm}$ are presented in Figure 13 . The bubbles in the wave-tip bubble cloud have the largest velocities as well as the largest size. The velocity is particularly high just above the bed at up to $3.5 \mathrm{~m} / \mathrm{s}$. During the initial stages of the swash flow on the slope, the front face of the bore is very steep and hence it continues to collapse shoreward which generates a jet that causes the tip to rush forward resulting in velocities that are much larger than the flow behind the tip. After a peak, the velocity decreases very rapidly and at the trailing edge of the wave-tip bubble cloud, the bubble velocities are approximately $2 \mathrm{~m} / \mathrm{s}$ and largely independent 
of vertical location. Behind the wave-tip bubble cloud and below the wave-plunge bubble cloud there are enough bubbles present to also obtain an estimate for the bubble velocity which continues to decrease but at a much slower rate than in the wave-tip bubble cloud.

The bubble velocities obtained above $z=60 \mathrm{~mm}$ are mostly attributable to the bubbles in the wave-plunge bubble cloud. The velocity of these bubbles also decreases with time and there is a small dependence on vertical location with the bubbles near the free surface having the smallest velocities. In addition, the velocities are clearly smaller than the velocities of the bubbles in the wave-tip bubble cloud as well as that of the bubbles that are present below the wave-plunge bubble cloud.
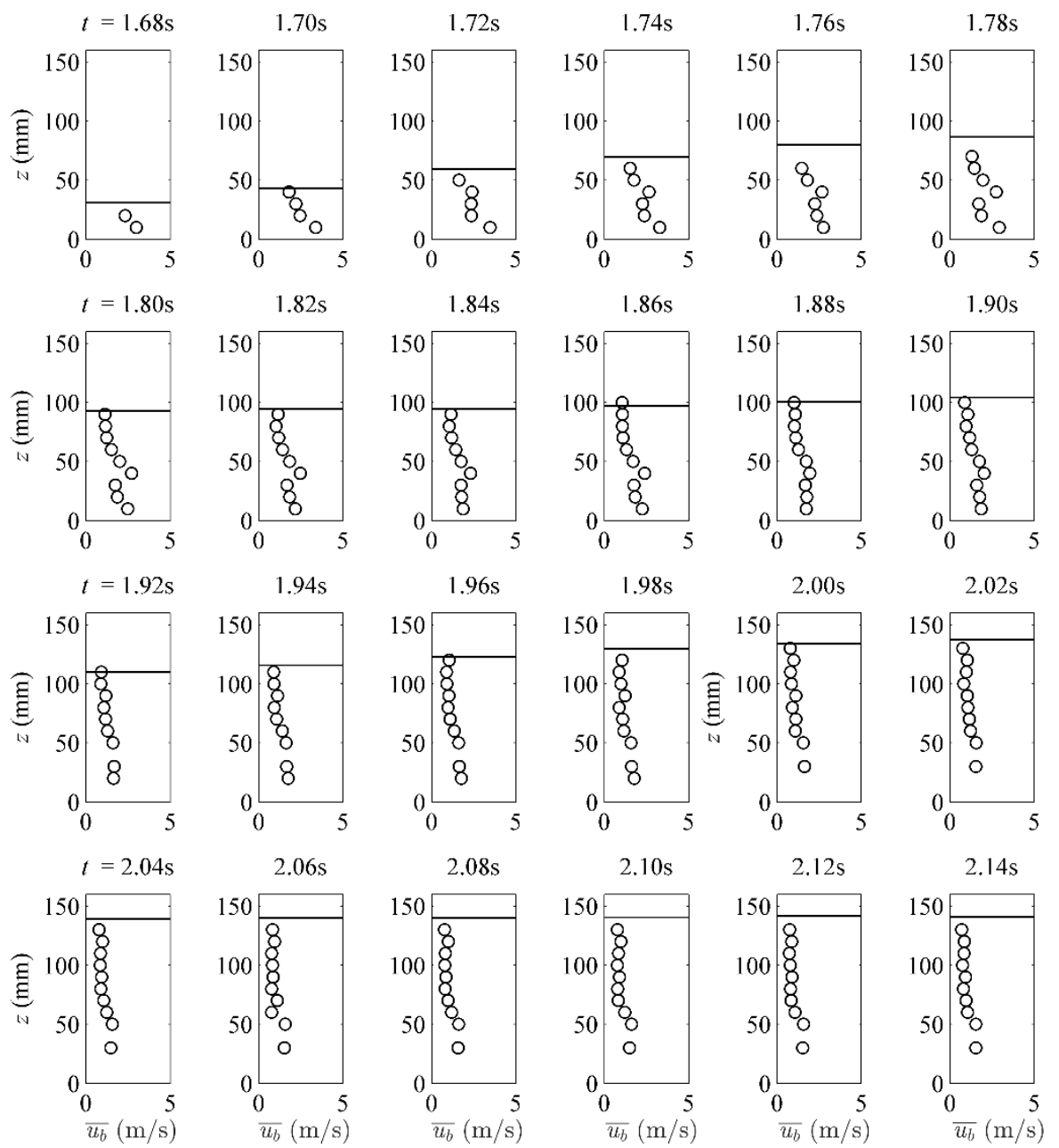

Figure 13 - Ensemble-averaged bed-parallel bubble velocity profiles at $x=162 \mathrm{~mm}$ from $t=1.68$ to $2.14 \mathrm{~s}$ in 0.02s intervals, horizontal black line indicates corresponding ensemble-averaged flow depth. 

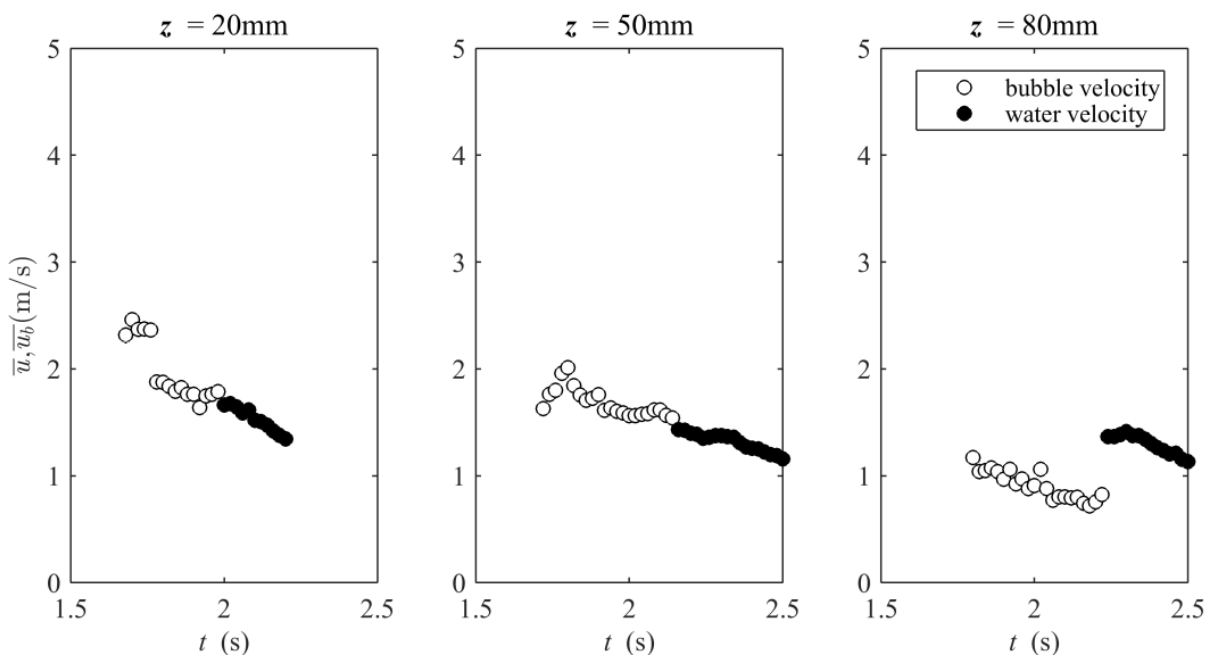

Figure 14 - Time series of ensemble-averaged bubble velocity and water velocity at $x=162 \mathrm{~mm}$ and $z=20 \mathrm{~mm}$, $50 \mathrm{~mm}$ and $80 \mathrm{~mm}$

The optical probes enable velocities to be measured where PIV cannot be used, hence yielding valuable data that has not been obtained before. As soon as the number of bubbles becomes too small, the velocity of the water can be obtained using PIV. Example results combining the two velocity time-series are presented in Figure 14. At heights where the wavetip bubble cloud is found (i.e. $z=20 \mathrm{~m}$ and $50 \mathrm{~mm}$ ) there is a smooth transition between the velocity of the bubbles and the water, whereas for the wave-plunge bubble cloud, at $z=80 \mathrm{~mm}$, there is a step change. It can be inferred that the ensemble-averaged bed-parallel velocity of the wave-tip bubbles is the same as the velocity of water that carries them, while the velocity of wave-plunge bubbles is slower. The latter is counter-intuitive, since the aeration process is natural, and air density is very low, so it deserves further consideration.

It is possible that at the time of entrainment of the bubbles in the wave-plunge bubble cloud, the bubble and mean flow velocities were similar as results by Kikkert et al. (2012) show that the velocity of the flow in the neighbourhood of the second plunge point was significantly smaller than at the initial shoreline location. That would indicate that the bubbles were decelerating more rapidly than the mean flow, and are not controlled solely by the mean flow. Research has repeatedly confirmed that the behaviour of bubbles is also affected by turbulent flow structures. For example, Tio et al. (1993) pointed out that bubbles were driven to the cores of eddies and Poorte and Biesheuvel (2002) and Aliseda and Lasheras (2011) showed that turbulence reduced the rise velocity. Direct investigations of the effect of turbulence on the bedparallel velocity of air bubbles are rare. Aliseda and Lasheras (2011) measured both the horizontal and vertical bubble velocities in a turbulent flow, but only presented the vertical velocities. Lin et al. (2012) investigated the entrained air bubbles in a hydraulic jump and measured both components of the bubble velocity using BIV as well as flow velocities using PIV. Their results showed that the air bubbles entrained into a steady state flow were controlled immediately by the mean flow, however, if the flow was highly turbulent and included regions 
of strong shear, bubbles no longer followed the mean flow and instead had a lower velocity of approximately 0.6 to 0.8 times the mean flow. The result from the present study are similar to those obtained by Lin et al. (2012) which indicates that the turbulence generated during the collapse of the bore rotates and deforms the bubbles and also affects their behaviour. However, to understand the details of the complex interaction between the turbulence and the bubbles (which themselves generate additional turbulence) requires simultaneous measurements of velocities of the bubbles and the surrounding water which were not obtained during the present experiments.
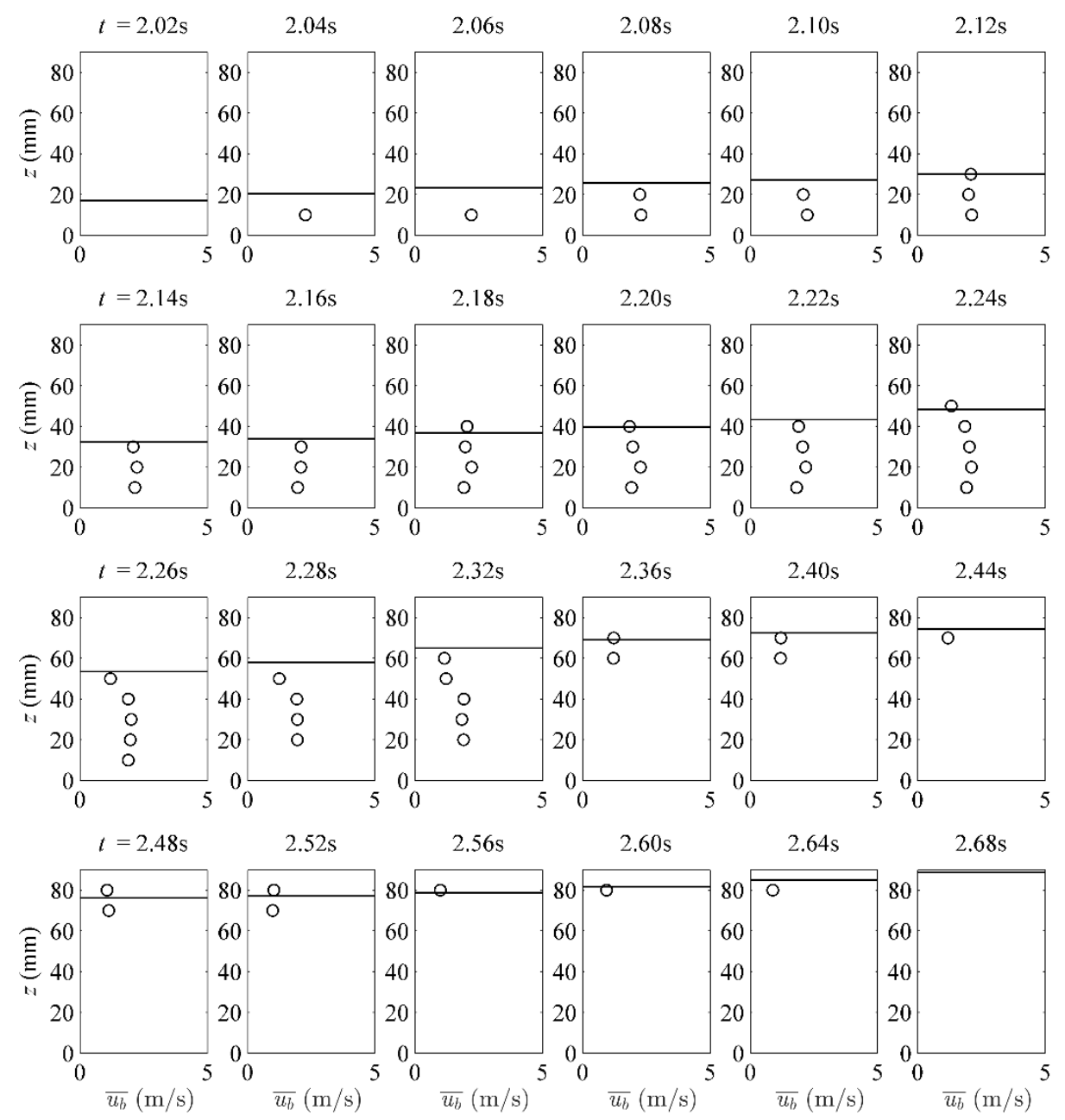

Figure 15 - Ensemble-averaged bed-parallel bubble velocity profiles at $x=1007 \mathrm{~mm}$ from $t=2.02$ to $2.68 \mathrm{~s}$ in $0.02 \mathrm{~s}$ or $0.04 \mathrm{~s}$ intervals, horizontal black line indicates corresponding ensemble-averaged flow depth.

The ensemble-averaged bubble velocity profiles at $x=1007 \mathrm{~mm}$ are presented in Figure 15. At this location the maximum velocity of the wave-tip bubbles is approximately half that at $x=162 \mathrm{~mm}$, since the face of the bore is less steep and hence a jet is not generated. The velocities of the wave-tip bubbles gradually decrease with time and are still larger than those of the bubbles remaining from the wave-plunge bubble cloud. Once again, the bubble velocities of 
the wave-tip bubble cloud transform smoothly into the water velocity (not shown), while the discontinuity for the bubble velocities of the wave-plunge bubble cloud are also still present. Further up the slope, the velocities of the bubbles decreases further because of the smaller velocity of the flow at the wave-tip. As all bubbles are locally entrained, the difference in the velocity between the bubbles in the wave-tip bubble cloud and the trailing bubbles disappears and so does the discontinuity with the water velocity.

\section{Discussion}

The ensemble-averaged volumetric flow rate per unit width of air, $\bar{V}_{a}(x, t)$, that passes through a measurement location is obtained by multiplying the ensemble-averaged void fraction by the ensemble-averaged bubble velocity and integrating over the flow depth:

$$
\bar{V}_{a}(x, t)=\int_{0}^{h} \bar{\alpha} \bar{u}_{b} d z
$$

The total ensemble-averaged volume of air per unit width, $\bar{V}_{a}(x)$, that passes through a crosssection in the swash zone is then obtained by integrating $\bar{V}_{a}(x, t)$ over the duration of the swash event. In practice, the duration is set to the time from bore arrival to flow reversal as all entrained air has escaped during the uprush. The total volume of the flow that passes through a cross-section, $\bar{V}_{t}(x)$, which includes air and water is obtained from the depth and depthaveraged velocity time-series. The results are presented in Figure 16 which shows that the total volume of entrained air that travels with the flow through the cross-section at $x=162 \mathrm{~mm}$ and therefore into the swash zone is approximately $2.5 \mathrm{~L} \pm 0.1 \mathrm{~L}$ per meter width which is approximately $1.0 \%$ of the total volume of the flow that travels past $x=162 \mathrm{~mm}$ during the uprush. At locations further up the slope, changes in the results are caused by the additional entrainment at the tip and the air that has escaped since the previous measurement location. At $x=1008 \mathrm{~mm}$, the total volume of air has reduced to about $0.5 \mathrm{~L} \pm 0.03 \mathrm{~L}$ per meter width or $0.3 \%$ of the total volume as the majority of entrained air present at $x=162 \mathrm{~mm}$ of the wave-tip and wave-plunge bubble clouds has escaped from the flow and the local entrainment rate of air has also reduced due to the less turbulent wave tip. For locations further up the slope the decrease in the total volume of air is more gradual as the local entrainment rate of air decreases further. At $x=3432 \mathrm{~mm}$, the total volume is close to zero and therefore the flow is essentially a one phase flow. All entrained air has escaped and no further entrainment occurs locally. The volume of air entrained by a plunging breaker in deep water was measured by Rojas and Loewen (2010). For a plunging wave with wave height $\sim 0.20 \mathrm{~m}$, they obtained a value of $18 \mathrm{~L}$ per meter width which is five times greater than the $2.5 \mathrm{~L}$ per meter width that entered the swash zone. This also 
indicates that a significant amount of entrained air has escaped the flow before it reaches the swash zone.

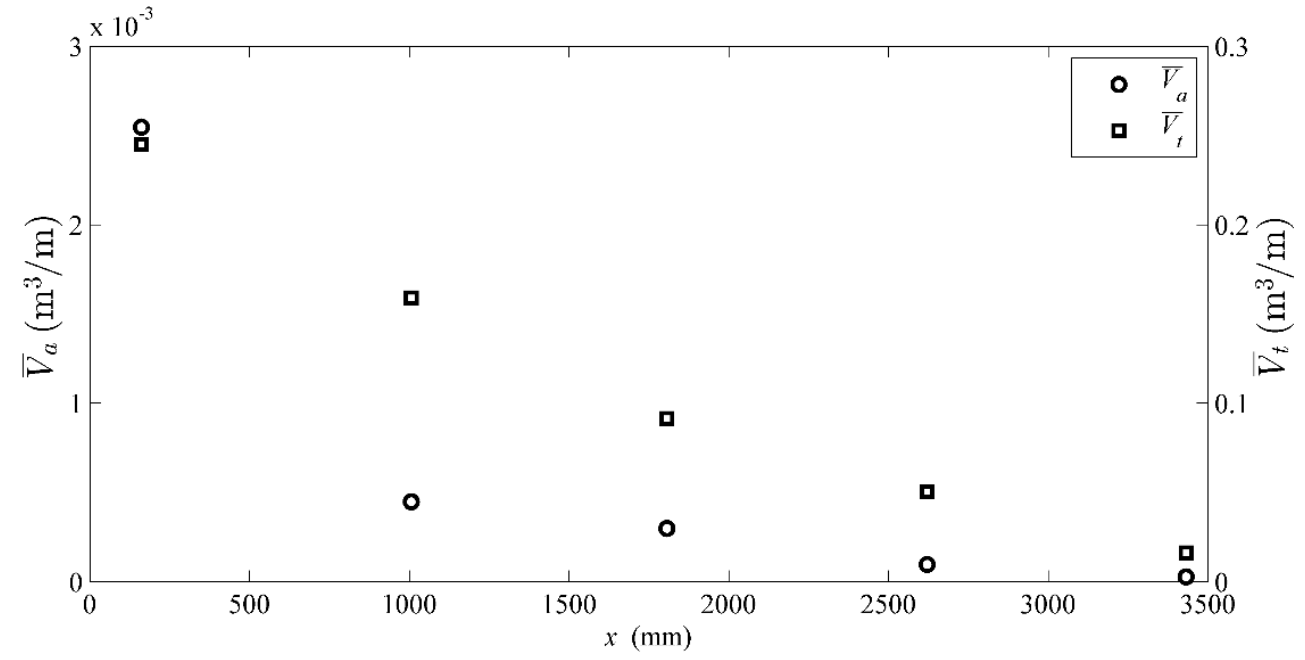

Figure 16 - Total volume of air and total volume of the flow per meter width that is present in the swash zone during the uprush

The entrained air increases the height of the free surface above the bed relative to a baseline where the flow consists solely of water. Integrating the void fraction profiles (Figures 8 and 9) yields the depth-averaged ensemble-averaged void fraction. When multiplied by the flow depth this yields the flow depth solely attributable to the entrained air, or alternatively the difference between the measured flow depth and flow depth without entrained air. Immediately after bore arrival at $x=162 \mathrm{~mm}$, the flow depth increases by approximately $6.0 \mathrm{~mm}$ as a result of the entrained air. The air depth remains relatively constant while the wave-tip bubble cloud with void fractions up to 0.20 passes the measurement location, but the relative contribution of air depth to the flow depth decreases from $15 \%$ to $5 \%$ as the flow depth increases from $40 \mathrm{~mm}$ to $110 \mathrm{~mm}$ during this time. At the trailing edge the air depth reduces to $2.2 \mathrm{~mm}$ and then increases again gradually to reach a peak of $4.7 \mathrm{~mm}$ at $t=2.12 \mathrm{~s}$ during the passage of the waveplunge bubble cloud. The flow depth is $141 \mathrm{~mm}$ at this time. From $2.26 \mathrm{~s}$ onwards, the void fractions are too small for there to be a difference in the flow depth with and without air. At $x$ $=1007 \mathrm{~mm}$, the maximum void fraction of 0.07 during the passage of the wave tip results in a maximum difference of up to $1.4 \mathrm{~mm}$ between the flow depth with and without air, while the flow depth during this time is approximately $30 \mathrm{~mm}$.

The increase in the flow depth due to the entrained air also represents additional potential energy that travels into the swash zone. This additional potential energy dissipates from the flow when the bubbles escape, assuming that the bubbles do not transfer energy to the flow while rising toward the free surface (Lamarre and Melville, 1991, Blenkinsopp and Chaplin, 2007, Hoque and Aoki, 2008). The potential energy per meter width, $P E(t)$, that is 
attributable to the entrained air depends on the volume of entrained air as well as its location relative to the free surface and is calculated as:

$$
P E(t)=\rho_{w} g \cos \alpha \int_{0}^{\bar{h}} \bar{\alpha} \bar{u}_{b}(\bar{h}-z) d z
$$

where $\rho_{w}$ is the density of water, $g$ the gravitational constant and $\theta$ is the angle of the beach. The total potential energy $P E_{t}$ is again obtained by integrating over the duration of the swash event which yields an estimate of just under $1 \mathrm{~J} / \mathrm{m} \pm 0.05 \mathrm{~J} / \mathrm{m}$ as a result of the $2.5 \mathrm{~L}$ per meter width of air that travels past $x=162 \mathrm{~mm}$. The majority of this potential energy is due to the wave-tip bubble cloud. Not only is the volume of air larger, as indicated by the larger void fractions, the average distance of the entrained air to the free surface is also larger as the bubbles were better mixed throughout the flow column while those in the wave-plunge bubble cloud were clustered near the free surface. Assuming that during the escape of the bubbles none of the potential energy is transferred back to the flow and neglecting the energy loss due to the fractioning of the large bubbles (Lamarre and Melville, 1991, Blenkinsopp and Chaplin, 2007, Hoque and Aoki, 2008), the energy loss related to the entrained air is equal to the potential energy of the bubbles. The current experimental results do not enable the volume of air that is entrained locally in the swash zone to be determined. Hence an estimate for the minimum energy loss for the whole swash zone attributable to entrained air is set equal to the potential energy related to entrained air at $x=162 \mathrm{~mm}$.

To determine the significance of this energy loss, an estimate for the total energy loss during the swash event is obtained. Firstly instantaneous time-series of the energy flux per unit area at $x=162 \mathrm{~mm}$ are calculated as:

$$
E_{f}(z, t)=\rho_{w} g\left(\frac{u^{3}}{2 g}+z \cos \theta \cdot u\right)
$$

To obtain the ensemble-averaged energy flux time-series per meter width, $\overline{E_{f}}(t)$, the instantaneous time-series, $E_{f}(z, t)$, are integrated over the flow depth and then averaged over the 50 repeated experiments. The instantaneous time-series are integrated first so that the turbulent kinetic energy is also included. To carry out the calculation it is necessary to obtain estimates for the velocity while the bubble clouds pass the measurement location (when it was not possible to use PIV). During the remainder of the uprush, a second order polynomial is an almost perfect fit for the ensemble-averaged depth-averaged velocity at $x=162 \mathrm{~mm}\left(\mathrm{R}^{2}=\right.$ 0.998). Hence estimates for the velocity immediately after bore arrival are obtained by extrapolation of the velocity time-series back to the time of flow arrival using this polynomial. To check these estimates the time-series of the total mass of water on the beach (i.e. shoreward of $x=162 \mathrm{~mm}$ ) is calculated firstly by a summation of the results of the mass flux time-series at $x=162 \mathrm{~mm}$ which uses the depth-averaged velocity estimates and assumes there is no 
entrained air and secondly by obtaining the area underneath the swash lens. Comparisons of the results from the two methods yields an $\mathrm{R}^{2}$ of 0.992 and hence the extrapolated data is used for the calculation of the energy flux.

The time-series of the ensemble-averaged energy flux per meter width at the initial shoreline is shown in Figure 17 and includes the results based on the measured and extrapolated data which are connected through a small discontinuity as the measured data include the turbulent kinetic energy while the extrapolated data does not. The rapid increase during a very short period after bore arrival is the result of the increase in the flow depth that is much greater than the decrease in the (extrapolated) velocity. The peak energy flux of approximately $450 \mathrm{~W} / \mathrm{m}$ coincides with the time when there is a significant reduction in the rate of increase of the flow depth. After flow reversal, the increase in the velocity combined with the slow decrease in the depth results in a more gradual increase in the energy flux out of the swash zone. Peak energy flux during the backwash is approximately $100 \mathrm{~W} / \mathrm{m}$ and occurs just before the time of maximum backwash velocity while the flow depth is decreasing rapidly.

The energy flux at the end of the measurement is negligibly small despite the non-zero depth and velocities. The rate at which the energy flux time-series goes to zero is therefore a more appropriate quantity for defining the end time of a single swash event than the depth and velocity time-series. The time at which the energy flux becomes less than $1 \%$ of the maximum backwash energy flux was used as the definition for the end time, which was found to be $t=$ $10.08 \mathrm{~s}$.

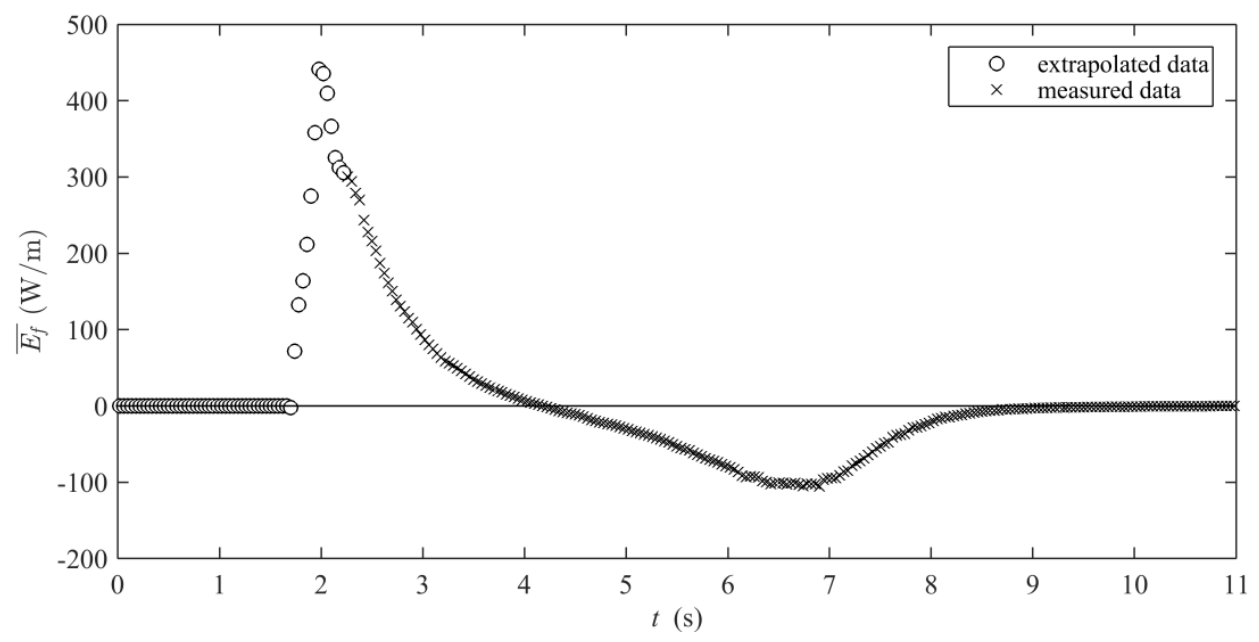

Figure 17 - Time series of ensemble-averaged energy flux at $x=162 \mathrm{~mm}$

The total energy dissipation in a swash event, obtained by integrating the time-series of energy flux shown in Figure 17 over the duration of the swash event, was found to be approximately $100 \mathrm{~J} / \mathrm{m}$. The minimum energy loss due to entrained air is therefore of the order of $1 \%$ of the total energy dissipation. Even taking into account the additional energy loss due to the local entrained of air within the swash zone, this percentage is significantly lower than 
those obtained in the deep water and surf zone of between 10 and 40\% (Lamarre and Melville, 1991, Blenkinsopp and Chaplin, 2007, Hoque and Aoki, 2008). The reasons for the smaller numbers in the swash zone are, firstly, that the highly aerated bore front that enters the swash zone is followed by a fast and highly turbulent flow of relatively long duration. This results in significant energy dissipation due to bore-generated turbulence and bed-generated turbulence (Kikkert et al., 2012). Hence the total energy dissipation is much greater than for a breaking wave in deep water or surf zone. Secondly, the volume of entrained air is relatively small because a large amount of entrained air during wave breaking, including all air entrained during the first plunge, has escaped from the flow before it reaches the initial shoreline location.

The findings presented in this paper are on experimental data obtained for only a single set of initial conditions In order to confirm their general application further experiments should be carried out. Firstly, different initial conditions may increase the total volume of entrained air in the swash zone, compared to the present study. These include a plunging wave that breaks much closer to the initial shoreline. The smaller interaction with the still water may reduce the volume of air entrained, but the air that is entrained during the first and second plunges has much less time to escape before it reaches the swash-zone. In addition, larger diameter sediments along the slope result in an increase in the turbulence at the wave-tip and therefore an increase in the importance of the locally entrained air.

Secondly, the present experimental setup involves a single dam break instead of a sequence of waves typical for the real swash zone. This means that further research is required to determine whether the results are representative of those obtained in real swash. In the present experimental setup the memory effects of vorticity and turbulence between successive swash events are absent., and there are no swash-swash interactions. Both phenomena are likely to enhance air entrainment, especially in the case of wave-backwash interactions when the opposite velocities of the two consecutive waves result in intense shearing and generation of strong turbulent vortices (Chen et al., 2016).

Suspended sediments may also affect the characteristics of the entrained air as the highest concentrations of suspended sediments and the largest void fractions occur at the wavetip (e.g. O'Donoghue et al., 2016). Finally, the effect of the salt concentration in the water requires further investigation as breaking waves in salt water are known to generate bubble clouds with a larger number of smaller bubbles and a smaller maximum bubble size than breakers in fresh water (e.g. Kolaini, 1998).

\section{Conclusions}

The details of entrained air in the swash zone as well as its effects on the hydrodynamics were investigated using laboratory experiments. An improved dam-break mechanism generated a single plunging wave that collapsed and formed a bore that travelled up an impermeable, sand 
rough beach with slope 1:10. Ensemble-averaged measurements of the hydrodynamics were obtained using a combined PIV/LIF system at a frequency of $50 \mathrm{~Hz}$ and 50 repeated experiments. Measurements of the phase fraction were obtained using an optical probe system at a frequency of $496.030 \mathrm{kHz}$. Ensemble-averaged void fractions were obtained using 50 repeated experiments and local time-averaging at a frequency of $50 \mathrm{~Hz}$. The optical probes also yielded the ensemble-averaged bubble size and bubble velocity. Detailed observations of the bubble clouds were obtained using a BIV system.

Analysis of the results gave new insights into the hydrodynamics of the flow. Fluctuations in the free surface are present throughout the swash event and these directly affect the bed-normal velocities. In addition, flow near the initial shoreline is affected by the change in direction of the flow from the surf zone into the swash zone and in the backwash acceleration is reduced due to the water present in the surf zone delaying the time when the flow becomes supercritical. Observations of the BIV images revealed that near the shoreline most of the entrained air is present in two compact bubble clouds that are transported with the flow into the swash zone. The first cloud is caused by local entrainment at the wave tip and the second are the remaining bubbles entrained at the second plunge point of the breaking wave. The maximum void fraction of the wave-tip bubble cloud is approximately 0.20 and that of the wave-plunge bubble cloud is 0.18 , the total volume of entrained air is $1.0 \%$ of the total volume of the flow and up to $15 \%$ and $3.3 \%$ of the flow depth are attributable to air for the two bubble clouds respectively. Further shoreward these values decrease rapidly as the majority of air entrained in the flow at the initial shoreline location has escaped the flow due to buoyancy and the local entrainment rate of air decreases as the wave-tip is less turbulent. The locally entrained air in the wave-tip bubble cloud results in large air cavities, with individual bubble diameters up to $20 \mathrm{~mm}$ and ensemble-averaged velocities up to $3.5 \mathrm{~m} / \mathrm{s}$, which develop rapidly into multiple smaller bubbles. The bubbles in the wave-plunge cloud are of more homogeneous size with ensemble-averaged diameter $1.6 \mathrm{~mm}$, but have velocities that are smaller than that of the mean flow indicating that they are not only controlled by the mean flow but are also significantly affected by turbulence. Upon entering the swash zone the entrained air has potential energy of $1 \mathrm{~J} / \mathrm{m}$. This energy dissipates from the flow when the bubbles escape and the minimum energy loss due to entrained air is of the order of $1 \%$ of the total energy dissipation that occurs during the single swash event.

In general, the characteristics of the entrained air are similar to those obtained after wave breaking in the surf zone and deep water. However, the dissipation of energy attributable to the entrained air is smaller because a significant proportion of the air entrained after breaking has escaped the flow before it reaches the swash zone and because the total energy dissipation in the swash zone is much greater due the highly turbulent nature of the flow. Therefore despite the reasonably high void fractions, the overall effect of the entrained air on the hydrodynamics 
of the flow was small, thus supporting the assumption that the fluid in the swash zone can be modelled as a single phase. However, this conclusion is based on experimental data obtained for only a single set of initial conditions.

The data reported here are available on request from the authors.

\section{Appendix: Post-processing of optical probe data}

The two-phase time-series obtained by the optical probes included all air, i.e. the air present at the measurement location before the arrival of the flow and the entrained air after bore arrival. The interest of the present study is the void fraction of air attributed solely to the entrained air and hence it was necessary to remove the air from the two-phase signal that was obtained before bore arrival for each individual run. From the two-phase signal the time of bore arrival could not be obtained by identifying the time at which the signal became zero for the first time as water drops or spray were present at the tip of the incoming bore and temporarily submerged the tip of the optical probe. Instead the time of arrival of the first bubbles was identified and the two-phase signal was set to zero before this time. The individual phase signal time-series also included air gaps that were too large to be bubbles. Instead these were the result of the tip of the probe temporally exiting the highly turbulent and three-dimensional flow. The BIV images were used to obtain a maximum bubble size at each measurement location. Any bubbles with a size that was larger than this maximum size were classified as air gaps and removed from the time-series.

Probe results at different measurement locations showed that the residence time of the entrained bubbles had a range from $0.2 \mathrm{~ms}$ to $4 \mathrm{~ms}$, corresponding to a frequency between $250 \mathrm{~Hz}$ and $5000 \mathrm{~Hz}$. The recording frequency of the probes at $496 \mathrm{kHz}$ was therefore sufficiently high to capture the detailed behaviour of the bubbles. To obtain appropriate ensemble-averaged void fraction measurements, the instantaneous results were time-averaged and ensemble-averaged. The time-scale used had to be long enough to appropriately represent the local time-averaging but not too long as it would remove important details from the bubble clouds. Example results for the ensemble averaged void fraction, $\bar{\alpha}$, time-series are shown in Figure 18. For a timeaveraging frequency of $500 \mathrm{~Hz}$, the void fraction time-series still has significant fluctuations of large magnitude and high frequency, indicating that individual bubbles in the flow still have a large effect on the result. These fluctuations have disappeared for a time-averaging frequency of $50 \mathrm{~Hz}$, instead the time-series consists of relatively smooth variations that nevertheless contain a substantial number of distinct local peaks and troughs. Decreasing the frequency further to $25 \mathrm{~Hz}$ also removes fluctuations at medium frequencies, however, at the same time the peak magnitudes of the void fractions are flattened and widened, indicating that at this 
frequency some of the important details of the bubble clouds are removed. Thus the timeaveraging frequency was set to $50 \mathrm{~Hz}$.

(a)

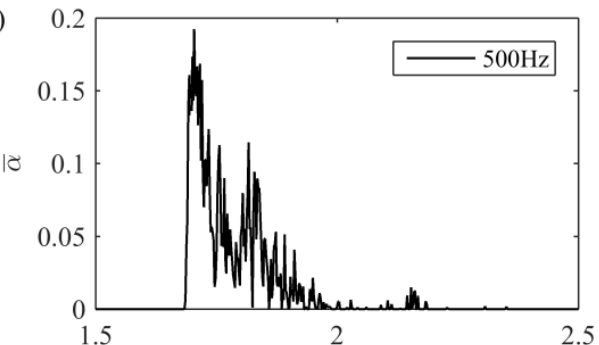

(c)

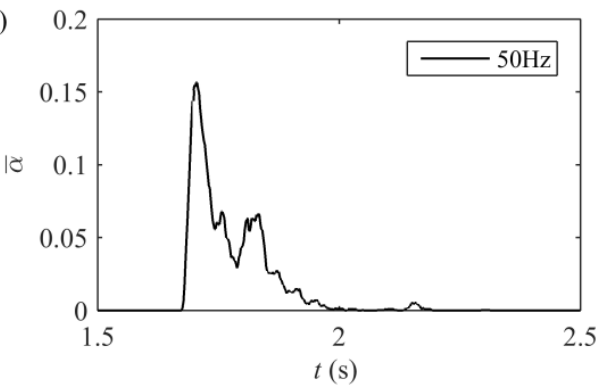

(b)

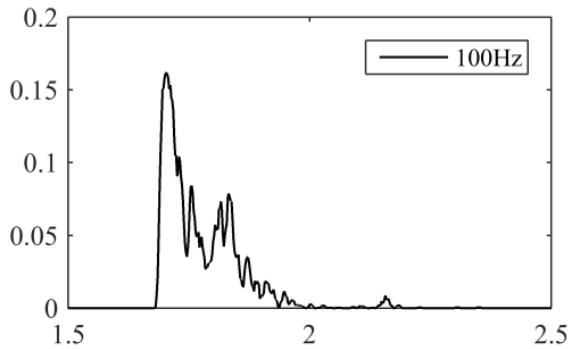

(d)

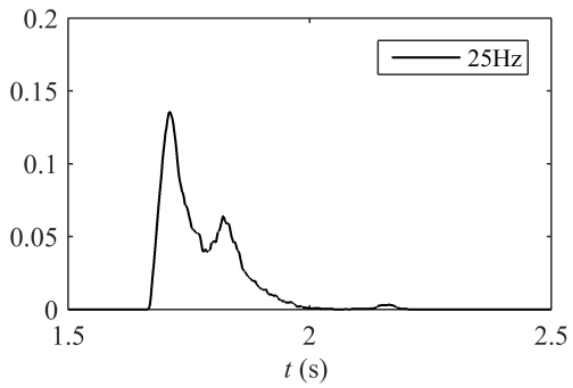

Figure 18 - Ensemble averaged void fraction time-series at $x=162 \mathrm{~mm}$ and $z=20 \mathrm{~mm}$ using time-averaging frequency of $500 \mathrm{~Hz}(\mathrm{a}), 100 \mathrm{~Hz}(\mathrm{~b}), 50 \mathrm{~Hz}(\mathrm{c})$ and $25 \mathrm{~Hz}(\mathrm{~d})$

(a)

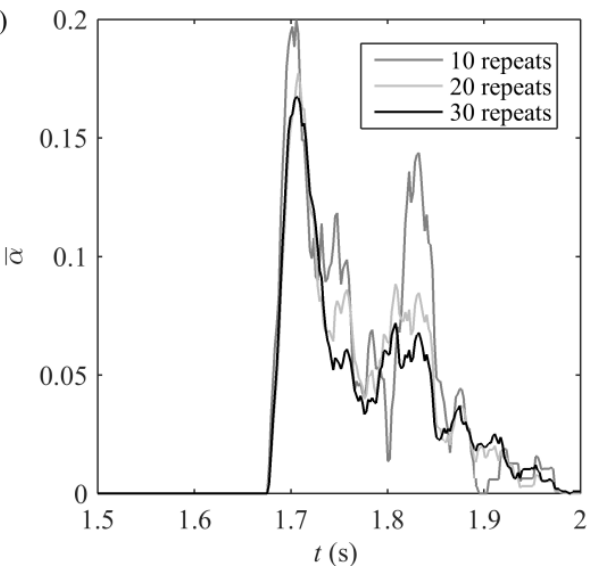

(b)

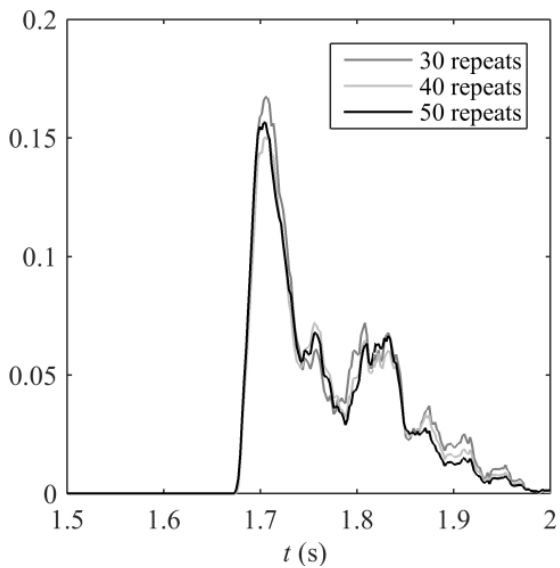

Figure 19 - Ensemble averaged time-averaged $(50 \mathrm{~Hz})$ void fraction time-series at $x=162 \mathrm{~mm}$ and $z=20 \mathrm{~mm}$ for 10 to 30 repeated experiments (a) and 30 to 50 repeated experiments (b)

To determine the number of repeat runs required, example ensemble averaged void fraction time-series using the time-averaging frequency of $50 \mathrm{~Hz}$ are shown in Figure 19 for different numbers of repeated experiments. Increasing the number of repeats from 10 to 30 results in significant changes in the void fraction time-series, however, increasing the number of repeats further from 30 to 50, the time-series are very similar. Therefore, for a time-averaging frequency of $50 \mathrm{~Hz}, 50$ repeated runs is a sufficiently large number that the results are independent of the number of repeats.

From the raw signal obtained by the optical probes, the SO6 software also calculated the chord length of each individual bubble that travelled past the instrument as well as its 
velocity using the assumption that the bubble is spherical. The individual bubble results from all 50 repeats and the time-averaging frequency of $50 \mathrm{~Hz}$ were used to calculate the ensemble averaged bubble size and velocity.

\section{Acknowledgements}

The authors gratefully acknowledge financial support from the Hong Kong Research Grant Commission under grant number 613711 and the TUYF Charitable Trust under grant number TUYF12EG06.

\section{References}

Aliseda, A., Lasheras, J.C., 2011. Preferential concentration and rise velocity reduction of bubbles immersed in a homogeneous and isotropic turbulent flow. Phys. Fluids 23.

Anguelova, M.D., Huq, P., 2012. Characteristics of bubble clouds at various wind speeds. J. Geophys. Res. C Oceans 117, C03036, doi:10.1029/2011JC007442.

Barnes, M.P., O'Donoghue, T., Alsina, J.M., Baldock, T.E., 2009. Direct bed shear stress measurements in bore-driven swash. Coast. Eng. 56, 853-867.

Barrau, E., Rivière, N., Poupot, C., Cartellier, A., 1999. Single and double optical probes in air-water two-phase flows: Real time signal processing and sensor performance. Int. J. Multiph. Flow 25, 229-256.

Blenkinsopp, C.E., Chaplin, J.R., 2010. Bubble size measurements in breaking waves using optical fiber phase detection probes. IEEE J. Oceanic Eng. 35, 388-401.

Blenkinsopp, C.E., Chaplin, J.R., 2007. Void fraction measurements in breaking waves. Proc. R. Soc. A Math. Phys. Eng. Sci. 463, 3151-3170.

Briganti, R., Dodd, N., Pokrajac, D., O'Donoghue, T., 2011. Non linear shallow water modelling of bore-driven swash: Description of the bottom boundary layer. Coast. Eng. 58, 463-477.

Brinkkemper, J.A., Lanckriet, T., Grasso, F., Puleo, J.A., Ruessink, B.G., 2016. Observations of turbulence within the surf and swash zone of a field-scale sandy laboratory beach. Coast. Eng. 113, 62-72

Cartellier, A., 1992. Simultaneous void fraction measurement, bubble velocity, and size estimate using a single optical probe in gas-liquid two-phase flows. Rev. Sci. Instrum. 63, 5442-5453.

Chanson, H., 1997. Air bubble entrainment in open channels: flow structure and bubble size distributions. Int. J. Multiph. Flow 23, 193-203.

Chanson, H., Brattberg, T., 2000. Experimental study of the air-water shear flow in a hydraulic jump. Int. J. Multiph. Flow 26, 583-607. 
Chanson, H., Manasseh, R., 2004 . Air entrainment processes in a circular plunging jet: voidfraction and acoustic measurements. J. Fluids Eng. 125, 910-921.

Chanson, H., Carosi, G., 2007. Turbulent time and length scale measurments in high-velocity open channel flows. Exp. Fluids 42, 385-401.

Chen, B.T., Kikkert, G.A., Pokrajac, D., Dai, H.J., 2016. Experimental study of bore-driven swash-swash interactions on an impermeable rough slope. Coast. Eng. 108, 10-24.

Cowen, E.A., Sou, I.M., Liu, P.L.-., Raubenheimer, B., 2003. Particle image velocimetry measurements within a laboratory-generated swash zone. Journal of Engineering Mechanics $129,1119-1129$.

Cumming, P.D., Chanson, H. 1997. Air entrainment in the developing flow region of plunging jets - part 2: Experimental. J. Fluid Eng. 119, 603-608.

Deane, G.B., 1997. Sound generation and air entrainment by breaking waves in the surf zone. J. Acoust. Soc. Am. 102, 2671-2689.

Deane, G.B., Stokes, M.D., 2002. Scale dependence of bubble creation mechanisms in breaking waves. Nature 418, 839-844.

Desombre, J., Morichon, D., Mory, M., 2013. RANS v 2-f simulation of a swash event: Detailed flow structure. Coast. Eng. 71, 1-12.

Elfrink, B., Baldock, T., 2002. Hydrodynamics and sediment transport in the swash zone: a review and perspectives. Coast. Eng. 45, 149-167.

Hinze, J.O., 1955. Fundamentals of the Hydrodynamic Mechanism of Splitting in Dispersion Processes. AIChE Journal 1, 289-295.

Hoque, A., Aoki, S.-., 2008. Air entrainment and associated energy dissipation in steady and unsteady plunging jets at free surface. Appl. Ocean Res. 30, 37-45.

Inch, K., Masselink, G., Puleo, J.A., Russell, P., Conley, D.C., 2015. Vertical structure of nearbed cross-shore flow velocities in the swash zone of a dissipative beach. Cont. Shelf Res. 101, 98-108.

Jiang, Z., Baldock, T., 2015. Direct bed shear measurements under loose bed swash flows, Coast. Eng. 100, 67-76.

Kalvoda, P.M., Xu, L., Wu, J., 2003. Macrobubble clouds produced by breaking wind waves: A laboratory study. J. Geophys. Res. C Oceans 108, C03207, doi:10.1029/1999JC000265.

Kikkert, G.A., Liyanage, T., Shang, C., 2015. Dam-break generated flow from an infinite reservoir into a positively inclined channel of limited width. J. Hydro-Environ. Res. 9, 519531.

Kikkert, G.A., O'Donoghue, T., Pokrajac, D., Dodd, N., 2012. Experimental study of boredriven swash hydrodynamics on impermeable rough slopes. Coast. Eng. 60, 149-166.

Kikkert, G.A., Pokrajac, D., O'Donoghue, T., Steenhauer, K., 2013. Experimental study of bore-driven swash hydrodynamics on permeable rough slopes. Coast. Eng. 79, 42-56. 
Kolaini, A.R., 1998. Sound radiation by various types of laboratory breaking waves in fresh and salt water. J. Acoust. Soc. Am. 103, 300-308.

Kucukali, S., Chanson, H., 2008. Turbulence measurements in the bubbly flow region of hydraulic jumps. Exp. Therm. Fluid Sci. 33, 41-53.

Lanckriet, T., Puleo, J.A. 2013. Near-bed turbulence dissipation measurements in the inner surf and swash zone. J. Geophys. Res. C Oceans 118, 6634-6647, DOI: 10.1002/2013JC009251.

Lamarre, E., Melville, W.K., 1992. Instrumentation for the measurement of void-fraction in breaking waves: laboratory and field results. IEEE Ocean Engineering 17, 204-215.

Lamarre, E., Melville, W.K., 1991. Air entrainment and dissipation in breaking waves. Nature $351,469-472$.

Lin, C., Hsieh, S.-., Lin, I.-., Chang, K.-., Raikar, R.V., 2012. Flow property and selfsimilarity in steady hydraulic jumps. Exp. Fluids 53, 1591-1616.

Lo, H.-Y., Park, Y.-S., Liu P.L.-F., 2013. On the run-up and back-wash processes of single and double solitary waves - An experimental study. Coast. Eng. 80, 1-14.

Longo, S., Petti, M., Losada, I.J., 2002. Turbulence in the swash and surf zones: a review. Coast. Eng. 45, 129-147.

Masselink, G., Puleo, J.A., 2006. Swash-zone morphodynamics. Cont. Shelf Res. 26, 661680.

O'Donoghue, T., Pokrajac, D., Hondebrink, L.J., 2010. Laboratory and numerical study of dambreak-generated swash on impermeable slopes. Coast. Eng. 57, 513-530.

O'Donoghue, T., Kikkert, G.A., Pokrajac, D., Dodd, N., Briganti, R., 2016. Intra-swash hydrodynamics and sediment flux for dambreak swash on coarse-grained beaches. Coast. Eng. 112, 113-130.

Petti, M., Longo, S., 2001. Turbulence experiments in the swash zone. Coast. Eng. 43, 1-24.

Pintado-Patiño, J.C., Torres-Freyermuth, A., Puleo, J.A., Pokrajac, D., 2015. On the role of infiltration and exfiltration in swash zone boundary layer dynamics. J. Geophys. Res. C Oceans 120, 6329-6350 DOI: 10.1002/2015JC010806.

Pjontek, D., Parisien, V., Macchi, A., 2014. Bubble characteristics measured using a monofibre optical probe in a bubble column and freeboard region under high gas holdup conditions. Chem. Eng. Sci. 111, 153-169.

Pokrajac, D., Kikkert, G.A., 2011. RADINS equations for aerated shallow water flows over rough beds. J. Hydraul. Res. 49, 630-638.

Poorte, R.E.G., Biesheuvel, A., 2002. Experiments on the motion of gas bubbles in turbulence generated by an active grid. J. Fluid Mech. 461, 127-154.

Pujara, N., Liu, P.L.-F., 2014. Direct measurements of local bed shear stress in the presence of pressure gradients. Exp. Fluids 55, 1-13. 
Pujara, N., Liu, P.L.-F., Yeh, H.H., 2015. An experimental study of the interaction of two successive solitary waves in the swash: A strongly interacting case and a weakly interacting case. Coast. Eng. 105, 66-74.

Rojas, G., Loewen, M.R., 2010. Void fraction measurements beneath plunging and spilling breaking waves. J. Geophys. Res. C Oceans 115, C08001, doi:10.1029/2009JC005614.

Ruju, A., Conley, D.C., Masselink,G., Austin, M.J., Puleo, J., Lanckriet, T., Foster, D., 2016. Boundary layer dynamics in the swash zone under large-scale laboratory conditions. Coast. Eng. 113, 47-61.

Ryu, Y., Chang, K.-., Lim, H.-., 2005. Use of bubble image velocimetry for measurement of plunging wave impinging on structure and associated greenwater. Meas Sci Technol 16, 1945-1953.

Sou, I.M., Cowen, E.A., Liu, P.L.-., 2010. Evolution of the turbulence structure in the surf and swash zones. J. Fluid Mech. 644, 193-216.

Sou, I.M., Yeh, H., 2011. Laboratory study of the cross-shore flow structure in the surf and swash zones. J. Geophys. Res. C Oceans 116, C03002, doi:10.1029/2010JC006700.

Stansby, P.K., Chegini, A., Barnes, T.C.D., 1998. The initial stages of dam-break flow. J. Fluid Mech. 374, 407-424.

Steenhauer, K., Pokrajac, D., O'Donoghue, T., Kikkert, G.A., 2011. Subsurface processes generated by bore-driven swash on coarse-grained beaches. Journal of Geophysical Research C: Oceans 116, C04013, doi:10.1029/2010JC006789.

Stokes, D., Deane, G., Vagle, S., Farmer, D., 2002. Measurements of Large Bubbles in OpenOcean Whitecaps, in Donelan, M.A., Drennan, W.M., Saltzman, E.S., Wanninkhof, R. (Eds.), Gas Transfer at Water Surfaces. American Geophysical Union, Washington, D. C.

Tio, K.-., Linan, A., Lasheras, J.C., Ganan-Calvo, A.M., 1993. On the dynamics of buoyant and heavy particles in a periodic Stuart vortex flow. J. Fluid Mech. 254, 671-699.

Wood, I.R., 1991. Air Entrainment in Free-Surface Flow: IAHR Hydraulic Structures Design Manual no. 4. Balkema, Rotterdam. 